\title{
Crónica de una etnia anunciada: Nuevas perspectivas de investigación a 10 años de vigencia de la Ley Indígena en San Pedro de Atacama
}

Alonso Barros VAN H. ${ }^{1}$

\section{RESUMEN}

La Ley Indígena chilena fijó el plazo de tres años para realizar un plan de saneamiento de títulos de dominio sobre las tierras individuales, comunitarias y patrimoniales de propiedad atacameña: han transcurrido 10 y estos derechos territoriales no se han respetado ni implementado. En tanto, las compañías mineras obtienen del gobierno concesiones en áreas respecto de las cuales éste percibe a cambio, ingresos por la venta, arriendo y concesión de tierras fiscales, así como por las servidumbres que imponen las faenas. Lo desigual de esta carrera propietaria entre indígenas, Estado y mineras se refleja en que las comunidades andinas de la II Región no han podido hacer efectivos sus derechos territoriales en tiempo y forma. Este ensayo describe cómo, de una manera similar a lo ocurrido en los demás países latinoamericanos, la política que consiste en demorar la implementación de los derechos territoriales reconocidos a los indígenas hasta su negación, le ha permitido a ciertos actores económicos y políticos expandir sus esferas de influencia sin trabas por tierras que beneficiarían del grado mayor de protección jurídico de que gozan las tierras indígenas en Chile. Se consideran algunas razones por las cuales las autoridades étnicas y municipales oficiales no han reclamado por el retraso en el saneamiento, ni por la reducción por vía administrativa y jurídica de las propiedades a regularizar. El caso nos lleva a formular nuevas preguntas de investigación acerca de los ciclos y modos de territorialización y diferenciación en Atacama, incluyendo los del poder estatal.

Palabras claves: territorialidad - propiedad - identidad - atacameños.

\section{ABSTRACT}

Chile's Indigenous Law set a three-year deadline to carry out the regularization of individual, community and patrimonial lands of Atacameño property: 10 have passed and these territorial rights have been neither respected, nor implemented. Meanwhile, mining companies operating

1 Instituto de Investigaciones Arqueológicas y Museo Arqueológico R. P. Gustavo Le Paige s. j. (IIAM), Universidad Católica del Norte, San Pedro de Atacama. Casilla 17, Correo San Pedro de Atacama, II Región, CHILE. Email: abarros@ucn.cl in the area have easily obtained diverse types of government land grants, sales and rentals from which the latter profits, as well as from compensations for the rights of passage that mining imposes on 'fiscal' land. The unevenness of this proprietorial race between indigenous people, the State and mining companies, is reflected in that the Andean communities of Chile's second region have been unable to make their territorial rights effective. This essay describes how, like in other Latin American countries, the politics that consist in delaying the implementation of indigenous peoples' territorial rights until their negation allow other economic and political agents to expand their spheres of influence without limits; and this, on lands that, in Chile at least, would otherwise benefit from the added legal protection of the Indigenous Law. We consider reasons why ethnic and municipal authorities and officials have neither objected to this delay, nor formally complained about the administrative and juridical reduction of the properties in the process of being regularized. The case leads us to formulate new research questions about the modes and cycles of territorialization and differentiation in the Atacama, including those of the State.

Key words: territoriality - property - identity Atacameños.

Recibido: marzo 2004. Manuscrito revisado aceptado: julio 2004.

\section{Preámbulo}

Ser mi propio informante en el caso que propongo, tiene a lo menos dos ventajas: a) se reducen los riesgos epistemológicos que plantea la interpretación, y b) mientras menos intermediarios haya en la cadena sintagmática de ideas, mayor la coherencia en la información que se produce. Parte del argumento se basa en experiencias propias, adquiridas como abogado de la Corporación Nacional de Desarrollo Indígena (en adelante CONADI) entre mediados del año 1994 -fecha en que se implementara efectivamente la Ley 19253 en San Pedro de Atacama- y los primeros meses de 1997. En esos casi tres años, la CONADI llevó adelante un acelerado proceso de constitución de Comunidades Indígenas entre los pueblos 
asentados en el Alto Loa y circundantes al Salar de Atacama. Esto ocurrió porque, para regularizar la propiedad indígena sobre las aguas superficiales, los diversos pueblos y ayllus de la zona debían previamente dotarse de una personalidad jurídica y territorial más representativa que la que hasta entonces les habían proporcionado sus Juntas de Vecinos y Centros de Madres. Una vez ejecutado el grueso del proyecto de aguas, la Oficina de Asuntos Indígenas de San Pedro de Atacama participó en el diseño del proyecto de catastro de tierras que debían ser saneadas de conformidad a la ley. ${ }^{2}$ A estas memorias profesionales, se agregan datos etnográficos recogidos posteriormente en el área (con breves estadías en los años 1998, 1999 y 2000) y experiencia en asuntos de tierra adquirida a lo largo de un trabajo comparativo que incluye dos años de investigación en Oaxaca (México), colaboraciones con diversas organizaciones indígenas de La Paz (Bolivia) e investigaciones intensivas en archivos.

Las conversaciones registradas desde julio de 2003 nos llevan a esbozar una descripción del proceso de titulación de las tierras comunitarias y patrimoniales atacameñas durante la última década. Lo que aquí se vierte son también, de alguna manera, las impresiones de alguien que vuelve a un pueblo donde vivió hace siete años, para encontrar cosas cambiadas y otras que no. Exploraremos algunas representaciones e interrelaciones propietarias e identitarias regionales y nacionales, retrazando procesos de apropiación y titulación de tierras contenidos en registros esparcidos de la historia. El presente trabajo espera contribuir a la comprensión de patrones de diferenciación territorial, política y económica en la segunda región. De un modo más general, quiere también sumarse al renovado interés que para la antropología reviste el estudio de las relaciones propietarias (Ingold 1986; Rose 1994; Hann 1998; Strathern 1999; Riles 1994, 1999 y 2001 Ms).

\section{Territorialidad, intermediación y propiedad: Relaciones cambiantes}

"Todos estos espacios [de la circumpuna] son esencialmente discontinuos, lo que plantea con fuerza el

\footnotetext{
2 Aunque he recogido observaciones etnográficas respecto a ambos procesos de titulación, los detalles por pueblo y en el tema de las aguas se analizarán en un trabajo posterior. Aquí solamente haremos una reseña global del proceso de reconocimiento de la propiedad atacameña.
}

problema de los límites. No nos referimos a las fronteras entre los estados-naciones de la región, ni a los límites político-administrativos nacionales, todos artificialmente impuestos, sino al manejo que hacen las propias comunidades indígenas para definir quiénes pueden y quiénes no pueden tener acceso a determinado espacio productivo... Aunque ancestralmente han estado en manos de las mismas comunidades [las tierras] son técnicamente consideradas como fiscales, lo que introduce un factor de inestabilidad" (Castro y Martínez 1996: 74-79).

El problema de los límites parece ser, en efecto, una constante en los Andes centro-sur y en el área considerada en este ensayo (actual provincia de El Loa, II Región de Antofagasta) (Figura 1). No queda claro, empero, que dichos "límites" tengan necesariamente que ver con la noción de espacio (discontinuo u otro). Tal como lo demostrara Casey (1996) desde la filosofía, o Tilley (1994) para la arqueología, la noción de "espacio" refleja una idea objetivada del entorno humano y mantiene innecesariamente la fractura mental cartesiana entre naturaleza y cultura. Distinguir territorialidades indígenas de la estatal por considerar que esta última es artificial, puede llevar a desconocer cómo éstas se han definido mutuamente a través de la historia, en una dialéctica tan sólo aparentemente cerrada. Cualquier lugar o persona es una amalgama de nociones territoriales estáticas y dinámicas, grados de rigidez y flexibilidad, opciones de ensanchamiento y achicamiento, y de funcionalidad (Sack 1986). Por eso, no es posible analizar los tejidos territoriales indígenas actuales sin a la vez considerar sus relaciones con la trama estatal: juntos han generado el campo discursivo y las formas heterogéneas de organización social y ocupación que forman parte de cierta experiencia compartida, la misma que es plasmada, por ejemplo, en artefactos burocráticos y elocuentes silencios, que quedan como prueba de rituales en otros tantos procesos territoriales. En efecto, las territorialidades no vienen dadas: son procesos que se construyen, delinean, ritualizan y transforman socialmente, sin cesar. Intentar leer entre y tras los escritos burocráticos se vuelve así una ejercicio antropológico y etnohistórico ineludible para distinguir con claridad cómo la voz "apropiada" contrapuntea con la "ajena" a lo largo del tiempo, y una línea de fuga territorial se separa de otra. ¿Pero qué diablos es "territorialidad”? ¿Qué es lo que hace? Re-tracemos a continuación algunos de sus elementos atingentes a nuestro caso: 


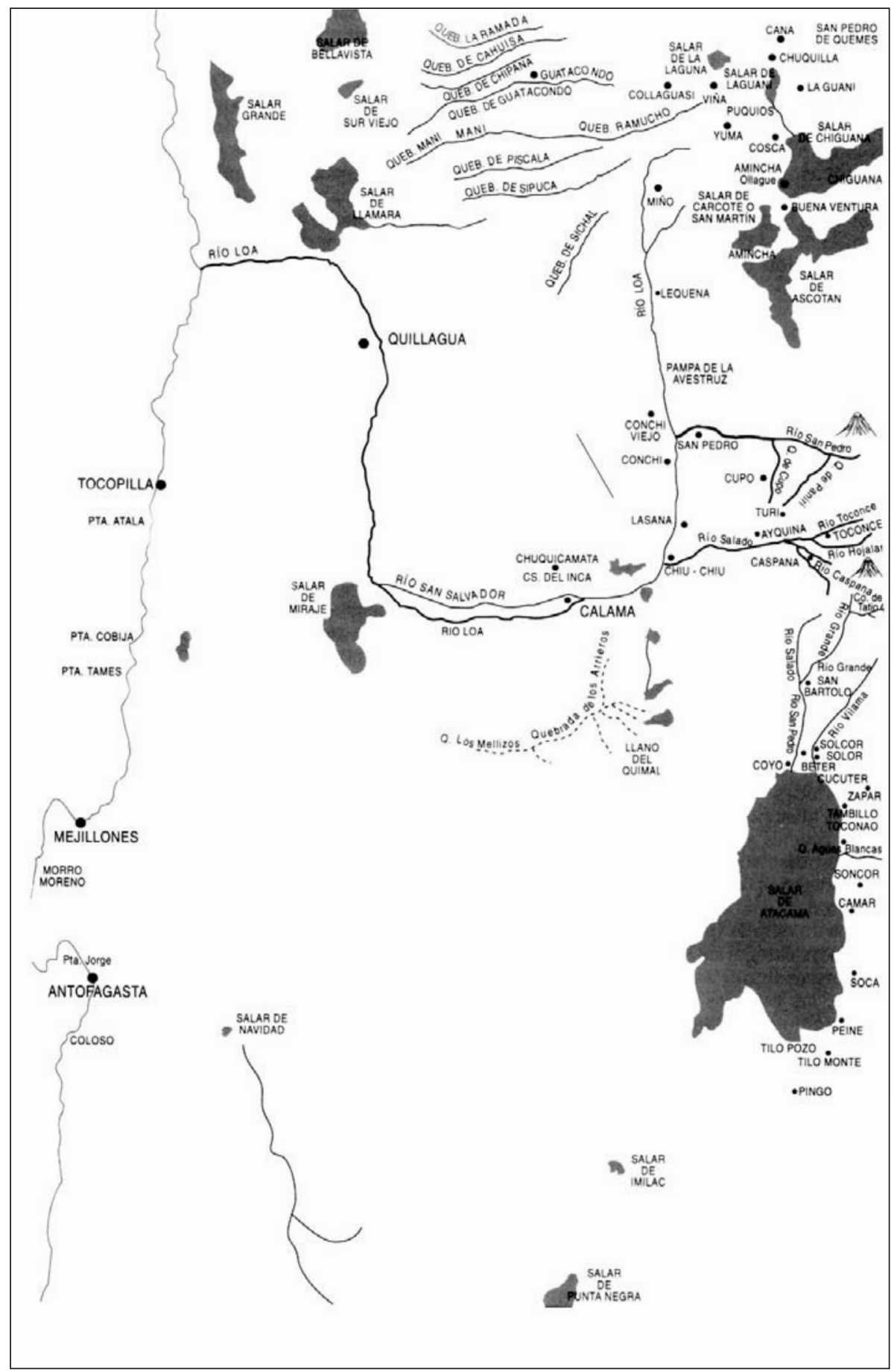

Figura 1. Poblados indígenas en la cuenca del río Loa y en la del Salar de Atacama. Tomado de Castro y Martínez (1996: 72).

a) Territorialidad como estado mental

La tradición legalista francesa define la territorialidad como "la personalidad del derecho". La an- gloamericana la considera, en cambio, como una expresión geográfica de poder personal y/o social. Sea "derecho" o "poder", ambas definiciones dan cuenta de una voluntad de territorio, el que la 
geopolítica adscribe comúnmente a los Estados. ${ }^{3}$ Esta territorialidad estatal se despliega discursivamente sobre la base de una institucionalidad normativa con axiomas llamados constitucionales. La funcionalidad más característica del Estado territorial viene dada por cuadros político-administrativos que gestionan unidades de planificación y ejecución nacionales y regionales. En el nivel local, es la municipalidad o la comuna la que articula con mayor fuerza la micropolítica de la ocupación y gestión del Estado. La Municipalidad de San Pedro de Atacama la ejerce especialmente en relación con la temática indígena, intermediando entre el Estado, el mediano y el gran capital minero e industrial, y espacios y organizaciones locales sobre las cuales ejerce cierta tutela legal (y cada vez más en los hechos). Por extensión, la estatal siempre se caracteriza como una territorialidad "intermediaria" con grandes vacíos de significación (¿qué significa la Provincia de El Loa, más allá de las prácticas administrativas que le están asociadas?).

Además de dividir administrativamente, el Estado homogeniza territorialidades "privadas" bajo un número limitado de tipos y sujetos propietarios excluyentes y catastrables: individual (persona natural), corporativa (persona jurídica), nacional (pueblo) y fiscales (Estado); cada una con sus subespecies. La personalidad territorial de la mayoría de los Estados latinoamericanos -incluyendo al chileno- se ha caracterizado, en cierto modo, por un repetido catastrar y dividir estas unidades económicas diferenciadas. Pero las propiedades o parcelas de poder que el fisco siempre está intentando medir, distribuir y redistribuir, son lógicamente anteriores a la noción misma de Estado (que no es sino otra acepción y forma de propiedad). ${ }^{4}$ Así, aunque la Constitución chilena "asegura a todas las personas (...) el derecho de propiedad en sus diversas especies sobre bienes corporales e incorporales" (19 $\left.\mathrm{N}^{\circ} 24\right)$, debe entenderse que las

3 La tensión territorialidad-territorio implica la incertidumbre asociada a toda re y desterritorialización. Elocuentemente, el Digesto sugiere que la etimología de la palabra territorium deriva del vocablo latino terrere (aterrar, espantar o aterrorizar), y en verdad la tensión territorial tiene algo de espantoso en nuestra tradición legal, donde la noción de propiedad se resumiría en la posibilidad de "aterrar" -o excluir mediante el terror- a alguien fuera de un "territorio".

4 Es elocuente la Constitución de la República, al sostener que los derechos de las personas son anteriores al Estado. "especies de propiedad" protegidas sólo son las que la ley designa como tales. Pero como veremos en el caso atacameño, las categorizaciones estatales suelen pasar por alto los múltiples niveles de tenencia y aprovechamiento de recursos que existen localmente, el continuo social que entrevera modos no propietarios (vinculados a sistemas, jerarquías y calendarios de acceso a recursos y la producción), formas y percepciones de propiedad de uso común y/o colectiva (p.e., los canales de regadío), y otras de propiedad individual, con variantes en cuanto a administración, usufructos, usos, posibilidades de producción, enajenación y beneficio, entre otros.

Así, el análisis antropológico no puede quedarse solamente con la territorialidad en clave estatal, sino que también debe ser capaz de reconocer aquellas que ésta trata de eclipsar y encoger. Sea la de las leyes y del Estado, o de los indígenas, de los ecólogos, misioneros, empresarios o mineros, para la antropología, cualquier manojo de signos o "poderes" distintivos que marque y haga efectiva la disposición, así como el acceso, uso y/ o goce exclusivo de recursos (tangibles e intangibles), es "propiedad". En efecto, las diversas sensibilidades y modos de apropiación, valoración y demarcación territorial en juego y las formas de exclusión a que dan lugar sólo pueden abordarse caso por caso; es decir, como intrincadas formas de "conocimiento local" (Geertz 1983). Debe entenderse que las opiniones y actitudes locales poco o nada tienen que ver con la legalidad y sus "propiedades" dominantes, tal como son propugnadas por nuestras clases políticas. Para éstas, el territorio estatal sería un tejido de adscripciones idealmente estáticas y manipulables desde el punto de vista político-geográfico. Lo que más caracteriza a los procesos de apropiación e intercambio de recursos y de conocimientos, sin embargo, es más bien el juego y mutación permanente de territorialidades, donde la ley es tan sólo uno de los términos posibles de relación. Así, por más que se articule en términos de territorio y propiedad, la territorialidad estatal no es por eso más real o de una ontología superior a la multiplicidad de territorialidades subyacentes y la Babel de formaciones históricas más o menos distintivas.

La construcción y movilidad permanente de territorialidades tiene estrecha relación con la presencia de oportunidades y limitaciones económicas y políticas, a su vez correlacionada con los 
diversos valores y grados de acceso a la información/poder territorial enhebrados en la multiplicidad de redes socioespaciales simbólicas y productivas. Cuando algún despliegue territorial logra excluir absolutamente a otros del acceso a ciertos recursos (p.e., mediante la guerra, fronteras duras, el secreto, o apoyándose en formas estructurales de violencia ligadas al capital), imponiendo "su" práctica excluyente, se puede hablar de una modalidad territorial propietaria o exclusiva. Nuevamente, esto no significa que tal o cual propiedad lo sea realmente o totalmente. Por eso, los llamados estudios de frontera han adquirido cierta relevancia como parte del canon antropológico. Aquí, más que estudios de la vida social en fronteras geopolíticas "literales" (Alvarez 1995), trabajaremos con una noción ampliada de frontera en tanto "frontera de sentido" conceptual como la que hemos visto girar en torno a las nociones de territorialidad y propiedad. Enseguida consideramos algunos elementos de las fronteras territoriales en sus aspectos propiamente antropológicos.

\section{b) Enfoque territorial}

Hasta ahora hemos propuesto una línea interpretativa que combina variables geográficas, identitarias y artefactuales. Para poder manejar las complejidades que envuelve este empeño, hemos venido trabajando con una herramienta analítica que las integra sin reducirlas: la idea de territorialidad, que hemos desarrollado sobre la base de Merleau-Ponty (1981 [1945]), Ardrey (1966), Barth (1969 y 2000), Deleuze y Guattari (1980 y 1991), Sack (1986), Ingold (1986 y 2000), Basso (1996), Feld y Basso (1996), Casey (1996), y Liffman (2002), y de nuestra propia práctica jurídica con comunidades indígenas.

Los estudios de territorialidad nacen en la ornitología para adaptarse paulatinamente en las ciencias sociales, siendo la geografía humana la disciplina que tal vez más ha desarrollado el concepto (Ingold 1986). Tras un breve recorrido por la noción de "paisaje cultural" (Bender 1993; Tilley 1994; Hirsch y O’Hanlon 1995; Barros 1998 y 1998 Ms; Castro 2002), la antropología social también ha venido a valorar el potencial analítico de este concepto, estudiando las fenomenologías, percepciones, sensaciones y prácticas biodiversas asociadas al "mundo de vida" territorial, lejos de la fractura cartesiana entre naturaleza y cultura, indígenas y estado, u otras abstracciones seme- jantes (Ingold 2000). Elaborando pues sobre la base de los resultados de nuestras investigaciones (Barros 1998, 1998 Ms, 2000 y 2003), consideramos que, de manera simultánea y no excluyente, la territorialidad humana es: 1) la estrategia por medio de la cual un individuo o un grupo intenta afectar o influenciar a gente, fenómenos y relaciones mediante la delimitación y aserción de control sobre un área geográfica; 2) un proceso de clasificación (diferenciación) activa por área que también envuelve comunicaciones a través de varios tipos de signos y formas, así como una serie de actividades de reforzamiento y reestructuración que a menudo revisten un carácter ritual (p.e., elaboración de títulos y recorridos de linderos); 3) un artefacto de la conciencia humana que cambia con el tiempo, una entidad compuesta por una gama variable de creencias, conocimientos, usos $\mathrm{y}$ formas de terratenencia, redes de intercambio y prácticas productivas, políticas y rituales; 4) una paleta de saberes que emerge de marcos institucionales y prácticas sociales, más que un conocimiento dado o impuesto automáticamente por éstos. A la vez fenomenología y saber emergente, el concepto de territorialidad apunta primordialmente a representar los conocimientos necesarios a la obtención de grados de satisfacción personal y/o social, know-how que sólo puede ser viablemente desplegado y transmitido sobre la base de la correlativa obtención de recursos tangibles e intangibles diseminados a lo largo de múltiples vías de comunicación. Pero, en tanto artefactos que encarnan formas de conocimiento y fenomenologías abiertas, las territorialidades humanas están en permanente mutación, y se van encogiendo o expandiendo, diferenciando, complementando y reforzando mutua e institucionalmente en el conocimiento y la palabra, así como en la práctica y en el intercambio; 5) aunque no se pueda negar que las territorialidades personales y sociales responden casi siempre a una racionalidad económica maximizadora, rara vez se agotan en ella: en contraste con la "propiedad", territorialidad es, ante todo, un principio de apertura o indeterminación entre dimensiones intelectuales y fenomenologías de inclusión y exclusión resentidas personal y/o socialmente que, aunque por fuerza inconmensurables, ganan con ser comparadas porque nunca son absolutamente incompatibles, antagónicas o intraducibles (Geertz 1983; Rosen 1997); 6) las territorialidades y las nociones espacio-temporales que las subtienden son eminentemente interpretables como procesos de 
apropiación, acumulación, comunicación e intermediación plasmados en intercambios materiales y transacciones que posibilitan una ulterior verificación (o, alternativamente, que generan perdurables malentendidos); 7) la fenomenología territorial, su simbología y rituales de exclusión e inclusión se traducen en una economía de "flujos de retornos" o beneficios distribuidos en conformidad a lógicas culturales que reflejan formas de conocimiento local vinculados, entre otros, al acceso y manejo de recursos característicos. Tales conocimientos locales asociados a plantas y a fauna, o sobre recursos minerales, técnicas hidráulicas y manejo agroganadero constituyen formas de soberanía intelectual y vinculaciones afectivas únicas, que van a su vez derivando en formas distintivas de demarcación, gestión y expresión identitarias.

El enfoque territorial que ensayamos pone a diferentes sujetos sociales en igualdad de condiciones para los efectos de la observación antropológica, sin por eso dejar de atender las asimetrías, las estructuras y los juegos de poder que intervienen en la resolución de conflictos puntuales. A la vez herramienta analítica y objeto de estudio etnográfico, la territorialidad permite combinar en terreno la recolección de datos empíricos asociados a lugares y rituales de emplazamiento, y la experiencia de las fenomenologías de memoria e identificación asociados a ellos. En tanto enfoque interpretativo, nos permitirá, por lo tanto, identificar y entender mejor los procesos socioterritoriales efectuados durante los períodos republicanos en el Norte Grande, a la vez que abordar una antropología cabal de las actuales dinámicas sociales, especialmente respecto de cómo se van formando conflictos y acuerdos para el manejo y distribución de recursos territoriales sobre la base de retóricas identitarias (no sólo étnicas).

Volviendo a las preguntas, ¿qué pasa, entonces, cuando hay varios repertorios propietarios en juego, y cada uno encarna valores, aspiraciones y nociones de justicia diferentes, como en San Pedro de Atacama?, ¿cuáles son las estructuras de oportunidades y de diferenciación territorial que configura a cada uno, y cómo derivan en procesos identitarios y dinámicas diferenciadas de distribución de beneficios?, ¿cómo se ha ido integrando y demarcando "la trama misma del juego segmentario en el sur andino" (Saignes 1985: 428), en relación con las sucesivas mareas globalizadoras, coloniales y postcoloniales?

Futuras investigaciones antropológicas ganarían con demostrar la posibilidad de que las diversas nociones locales y regionales de restricciones de acceso a áreas productivas determinadas, los intercambios entre ellas, y la distribución de los beneficios correspondientes, se traducen en procesos identitarios, y no a la inversa. ${ }^{5}$ Esto ha sido insinuado como una alternativa de explicación plausible por J. L. Martínez, quien sumando sus conclusiones a las interpretaciones que Wachtel y Saignes hacen de los registros históricos reseña cómo las adscripciones identitarias o etnoclasificatorias a menudo correspondían a descriptores geográficos, administrativos y/o productivos que dependían de la manera en que los funcionarios primero del incazgo y luego de la corona- percibieron las formas de producción indígenas y la necesidad de catastrarlas con precisión para colectar tributo (1998: 69). ${ }^{6}$ Es también posible que las denominaciones étnicas coloniales hayan correspondido, inicialmente, a un reconocimiento de los gobiernos territoriales indígenas y sus jefaturas tradicionales (cacicazgos, curacazgos u otros): así, los "atacamas" podrían haber sido aquellos que reconocían la autoridad de los caciques de los ayllus de Atacama. A estos intermediarios étnicos (en el sentido expuesto) les tocaba fiscalizar una amplia red de personas e intercambios cuyo funcionamiento circuital obligaba a mante-

5 La escasez bibliográfica y los vacíos etnográficos destacados por Castro y Martínez (1996) dificultan la comprensión más cabal de los procesos y protagonistas en cuestión. Siguen faltando datos para precisar y definir rasgos característicos de la etnia atacameña, de sus líderes, y de sus relaciones y diferencias tanto con los antiguos como con los actuales habitantes de la zona. No hay estudios recientes sobre las relaciones de parentesco y organización social, ignorándose, por ejemplo, el rol articulador general de los ayllus de San Pedro de Atacama. Tampoco existen análisis sistemáticos sobre cosmovisión, clasificación y redes de significación (los trabajos de Castro constituyen una valiosa excepción en ese sentido). Los mecanismos de solución de conflictos territoriales locales y las redes de relación transfronterizas tampoco se han estudiado sistemáticamente, ni la vigencia intelectual y etnográfica de los cerros como autoridades distributivas de agua, ganado, vientos, riquezas, salud, entre otros.

6 Viene al caso recordar que el origen etimológico de la palabra "tributo" es "tribu". 
ner mecanismos de control social y económico a larga distancia. Puede entonces que las identidades étnicas transmitidas por el sistema administrativo colonial sean un efecto de las exigencias tributarias impuestas al cacique y a su personalidad territorial o "cacicazgo". Esto podría concordar con el hecho de que, en algunos documentos sobre linderos, uno de los límites entre territorialidades regionales se describía como aquel lugar "donde se sientan a conversar" los gobernadores de una y otra parte (Paz Soldán 1878: 51). En este caso, el lindero es concebido más como punto de encuentro que como línea de separación (p.e., "en ese lugar o cerro nos encontramos con los del otro lado"). Conforme a la perspectiva territorial que venimos ensayando, puede que, al igual que en otras partes de América Latina, los límites fueran concebidos "medievalmente" como descriptores de poderes personales y autoridad distributiva (cacicazgos, jefaturas), más que geográficamente.

El caso atacameño invita a explorar el contexto socioeconómico en que se inscriben los procesos de identificación, la relación entre identidades y los ciclos y modos de diferenciación territorial a que pueden o no dar lugar, así como el despliegue consiguiente de repertorios de propiedad e identidad específicos. Aunque sobresalga actualmente el registro propietario formulado en clave estatal por medio de cada vez más y mejores títulos de tierras (Muñoz 1999), faltan estudios respecto del fenómeno creciente de "tomas" de terreno en San Pedro de Atacama indígena, o sobre el $20 \%$ de la población actual del oasis que es boliviana y el rol ambiguo de estos nuevos contingentes en las dinámicas étnicas regionales.

Se deberá explorar hasta qué punto la personalidad atacameña es definible en términos étnicos y/o patrimoniales como los fijados por ley (declinados a partir del control de recursos locales y redes regionales), o si es más bien de tipo direccional, es decir, orientada por movimientos y oportunidades económicas que favorecen a cierta clase constituida en intermediaria etnopolítica en el puerto "seco", de "altura" o de "sierra" que es San Pedro de Atacama. Será posible demostrar si y cómo una personalidad o un grupo caracterizados en términos de movilidad son más propensos a expandir y regular mecanismos de poder, comunicación y negociación política intra e interétni- cas, que a atender temas relacionados con la propiedad sobre asentamientos o espacios. Tal como lo hemos venido insinuando, esta última parece ser la situación vigente en San Pedro de Atacama. Una breve reseña del caso tal vez pueda reforzar algunas de las ideas planteadas.

\section{Identidad y propiedad: Forjando memorias proyectistas mediante verificaciones propietarias asistidas y autoritarias}

El retraso en la implementación y verificación territorial ordenadas por la Ley Indígena justifica hacer una "transitología" de cómo ha operado el "se acata pero no se cumple" estatal respecto de las territorialidades en cuestión, con énfasis en lo que dice relación con la territorialidad minera. ${ }^{7}$ El apartado que sigue describe cómo el proceso diferenciador de la propiedad (catastro y saneamiento) que se ha venido desarrollando en San Pedro de Atacama desde 1993 ha sido casi enteramente decidido e implementado desde el Estado, sobre la base de interpretaciones autoritarias y desajustadas que desconocen algunos elementos esenciales y característicos de las complejas territorialidades que operan en la región. Ilustraremos el poder tecnocrático de ciertos agentes fiscales en los procesos territoriales reseñados, para intentar elucidar cómo éstos han contribuido a generar una suerte de codependencia identitaria. Antes de pesquisar sus ribetes, resumiremos algunas de las impresiones recogidas al regresar a San Pedro tras algunos años de ausencia. De ahí intentamos una explicación respecto a lo ocurrido en el lapso de tiempo que intervino.

\section{a) Tiempo cero: Algunos estereotipos} locales de la identidad

En agosto de 2003, en un local que sirve de restaurante y centro de diversiones para la juventud san pedrina-calameña más pudiente, me habla un desconocido desde lo alto de sus veintitantos años, con aires de compartir alegremente el moderado estado de ebriedad generalizada. Tal vez creyendo que yo era turista $-\mathrm{o}$ afuerino o santiaguino o

\footnotetext{
7 Subvierto el uso negativo que Gledhill hace del término "transitología" (2002: 501-524) para resaltar la política de tiempos (ver Greenhouse 1996) magistralmente ejemplificada en Chile por el artículo $3^{\circ}$ transitorio de la Ley Indígena.
} 
muy rubio o qué más da- me dijo: "Escúchame, yo soy líder nato atacameño, Lican Antai, aquí mando yo, soy un jefe reconocido, pregúntale a quien quieras. Yo defiendo a la identidad atacameña, a mi cultura".

Hace siete años, los conceptos que vertió este joven eran de uso casi exclusivo de disciplinas sociales tales como la antropología, la sociología y afines. Entre 1994 y 1997, nunca las había oído en boca de los adolescentes atacameños a quienes frecuentaba: todavía no se producían los efectos "etnificantes" de la Ley Indígena. Corriendo el mes de julio de 2003, y posiblemente por vez primera en la oscura historia política de San Pedro de Atacama, amanecieron rayadas con pintura negra las paredes blanqueadas con cal que bordean las calles Caracoles y Domingo Atienza: "VIVIR CON IDENTIDAD LIKAN ANTAI" rezaba uno, "LIKAN ANTAI IDENTIDAD PUEBLO ATACAMEÑO" afirmaba otro, y "FUERA LA MAFIA" remataba el último que pude ver. Consternados, algunos políticos y funcionarios locales con quienes me encontré casualmente (particularmente puntillosos en lo de "ser atacameños") comentaban: "Qué descriteriados estos jóvenes. Cómo entenderlos... ¡Teniendo todos los espacios para expresarse democráticamente!"; para luego preguntarse, preocupados: “ ¿Quiénes serían la mafia?” (M. S. 50 años; M. E. P., 49 años).

Cuando quemaron los principales santos de la Iglesia de San Pedro, el 13 de febrero de 2001, de inmediato las autoridades locales asumieron que el atentado había sido obra de afuerinos desbocados, "jipis" que seguramente actuaron bajo el influjo de drogas y alcohol. Luego corrieron otras voces, diciendo que los vándalos sacrílegos habrían pertenecido a cierta secta evangélica radical. El caso es que hubo una pequeña procesión de desagravio a las imágenes, durante la cual algunos notables atacameños, airados, profirieron insultos de grueso calibre contra los afuerinos (según la versión de testigos presentes, abarcando explícitamente a los del pueblo de Talabre en ese apelativo). Una de las iglesias evangélicas hizo su propio acto de reparación, con una ceremonia en el patio del templo que no fue del agrado de todos los feligreses católicos, los que tomaron el acto por una provocación. Algún tiempo después se supo que las averiguaciones habían sindicado a los malhechores: entre ellos, una joven atacameña. El atentado, entonces, tenía visos de haber sido... jun montaje étnico! Por eso señalan -enterados- los chismosos, que a pesar de que estos incidentes dieron lugar a un temporal de violencia antiafuerino, la tormenta amainó, y nunca más se volvió a tocar públicamente el asunto. ${ }^{8}$

El punto es que palabras tales como "etnia", "identidad", "cultura", "sitios culturales sagrados", "tierras tradicionales", "autonomía territorial", "multi, pluri, e intercultural", "pluriétnico" y neologismos científico-sociales de corte similar, aparecen hace poco más de 10 años en las charlas y en la web, cruzando por bocas y debates. Ahora ya no sólo están en las leyes, los tribunales y los despachos ministeriales, sino que también por las calles y paredes de San Pedro. Aunque no se sepa muy bien para qué sirven exactamente, o a qué se refieren, tienen un poder de sugestión innegable en la compleja trama política chilena. En San Pedro, pareciera que de alguna manera reflejaran el creciente desasosiego nacido del indigenismo asistencialista y clientelista promovido desde el Estado, con su correlativo "proyectismo" étnico. Surgidos a partir de las relaciones legales privilegiadas que el Estado entabló o fijó con "sus" etnias a partir de 1993, tales conceptos han ido alimentado, reforzando y validando un discurso identitario micropolítico excluyente entre los jóvenes san pedrinos que han accedido a mayores niveles de educación o más expuestos a los debates identitarios actualmente en boga en otras partes del país. El desarrollo de este identitarismo filolegal también puede deberse al limitado horizonte de oportunidades económicas que estrecha al mayor número de la población, y contrasta con el que traen los recién llegados, ávidamente convencidos de poder agenciarse un buen pasar en el emporio turístico san pedrino.

Las insatisfacciones más profundas se pueden palpar casi solamente en el nivel local, en el en-

\footnotetext{
Un año antes, en vísperas del Día de la Raza, desconocidos intentaron quemar el Museo local donde descansan -protegidas- un número importante de osamentas ancestrales. Nunca se supo quiénes habían sido los autores, pero las sospechas apuntaban nuevamente a una o dos personas con nociones particularmente atrabiliarias de su identidad Gundermann (2002) ensayó una descripción pormenorizada de estos episodios locales, indicando su posible relación con los procesos identitarios y el desencanto juvenil que se ha venido produciendo en la localidad grosso modo, desde la implementación de la Ley Indígena.
} 
cierro de la casa: a la escasez de expectativas que padecen los jóvenes nativos, se suman las preocupaciones de las generaciones antecedentes. Al encontrarme con los padres y abuelos, conocidos y amigos de hace siete años, y tras saludarnos, invariablemente mencionan sus pleitos pendientes con algún vecino o pariente, detallan sus costosos e interminables juicios por tierras llevados varias veces ante la Corte Suprema (M. C. 65 años), intentos judiciales por resolver una herencia complicada (F. T. 68); o una venta hecha de palabra (M. A., 55 años), o algún litigio por un "localcito" y otras propiedades litigiosas en Calama (T. M., 63 años). Este pleitismo intestino -con seis "casos sociales" propietarios declarados y en plena ebullición, incluyendo desalojos forzados con auxilio de carabineros- responde directamente al ambiente de fuerte especulación inmobiliaria asociado al turismo. Aunque este problema no está claramente vinculado al "tema étnico" por mis informantes, creo que lo interpela directamente al trastornar algunos elementos básicos de la vida en los oasis atacameños, incluyendo algunos valores territoriales asociados al parentesco, por ejemplo, formas de endogamia propietaria. Claro que las propiedades de los agricultores que tradicionalmente han poblado los ayllus aumentan de valor a una velocidad azorante. ¡Si cualquier chacrita de menos de una hectárea con su choza puede llegar a valer sus buenos 30 millones de pesos! Y, mañana, jotros cinco millones más! Muchos de los que se fueron a Calama a estudiar y/o trabajar en Chuquicamata prometiendo nunca jamás volver a vivir en las duras condiciones rurales del San Pedro de Atacama de hace 20 años, tienen ahora los ojos clavados en las miserables herencias de sus abuelas y abuelos que se quedaron a morir en sus ayllus... En la medida que la tierra se ha vendido a gente que invierte pequeños y medianos capitales en proyectos recreativos y/o turísticos, se han ido desplazando las familias agricultoras: "A los atacameños nos están orillando, los que guardamos las costumbres vamos quedando en las puras orillas no más" (W. L. 32). Uno de los efectos identitarios directos de este proceso propietario es que la gente que viene llegando compra terrenos y se queda a vivir es considerada responsable del orillamiento y expulsión atacameña. Desde sus casitas de material y calamina, con baños y cocinas subsidiados en las nuevas poblaciones y "tomas" que han crecido en torno a los ayllus, algunos de los hijos de los que vendieron tierras agrí- colas consideran a los recién llegados como usurpadores. La élite política san pedrina, sin duda debido a un sentimiento de pérdida de control territorial, tiende más bien a avivar esos sentimientos, asegurando su clientela local. Así, algunas formas distintivas de esta memoria práctica y sus formas de territorialización se manifiestan, por ejemplo, en las diferencias entre personas "nacidas y criadas" en el lugar (que se hicieron de esa tierra) y que siguen "la costumbre", en oposición a los nacidos que, no criados en el lugar, retornan al pueblo luego de muchos años de estar afuera, para quedarse. También actúan pandillas étnicas de corte urbano.

Entre los tipos de "afuerinos" que señalan los "nacidos y criados" y los "retornados", destacan los santiaguinos por su prepotencia; los ovallinos y otros "huasos" de la III y IV región tampoco han gozado de buena reputación. Hasta no hace mucho, las gentes de esas partes eran los más cercanos por el lado de Chile: hay historias de faldas y escándalos que involucran al "huaso" nortino, mezcla de minero, arriero y vagabundo. ${ }^{9}$ Por razones diferentes (aunque con los mismos efectos diferenciadores) se distingue a los "jipis" que empezaron a llegar -algunos para quedarse- hacia fines de los $70 .{ }^{10}$ En cuanto a los bolivianos ("taiwaneses o bolis") que inmigran desde siempre a San Pedro en busca de oportunidades laborales, se puede apreciar algo así como sentimientos encontrados de parte de mis informantes: hay una cierta condescendencia con ellos por su pobreza de "gente humilde", pero también transpira un extraño y a menudo conflictivo sentimiento de cercanía con el "paisanito" altiplánico, ese que trasciende las fronteras literales. En el apartado siguiente se reconstituyen algunos procesos y episodios de diferenciación identitaria nacional y

\footnotetext{
9 W. L. (36 años) cuenta cómo hace unas décadas un huaso, don Juan, se llevó a María M. "pa'l sur”, quedando ella, ipso facto, desheredada: "Antes, los abuelos no permitían que las mujeres de acá se casaran con gente de afuera". Los problemas de tierras derivados de este episodio (hace más de 50 años) han tenido repercusiones hasta el día de hoy.

10 Gundermann (2002) agrega pandillas calameñas como "reventados", "cumas", "camboyanas", "boy scouts", "cuicos" y otros retornados ocasionales. Pero la lista podría seguir en función de un contingente faenero de obreros temporales, población flotante y mutante que suma y resta todas las diferencias étnicas imaginables.
} 
regional, algunos de cuyos papeles sobrevivientes nos hablan de estas territorialidades subyacentes.

b) Territorialidad india, territorialidad estatal: Una historia cruzada por preguntas de investigación

¿Qué formas territoriales y propietarias surgen de las geografías de poder locales y regionales, tanto estatales como étnicas u otras? ¿Cuáles son las pautas de diferenciación identitarias que las van distinguiendo? ¿Quiénes son sus sujetos, sus objetos, sus tiempos, o son acaso estas categorías del todo inapropiadas? ¿Existe algún corpus de conocimientos y prácticas que, identificable como "territorialidad atacameña", esté imbricado con -a la vez que se distingue de- un canon regional andino a su vez claramente separado del andamiaje mental estatal, más allá de lo que representa la noción de "usos y costumbres" locales? ¿Cómo se podría caracterizar "la personalidad territorial" atacameña en su mutua constitución con aquella otra territorialidad estatal, supuestamente "artificial", que desestiman Castro y Martínez (incluyendo, sin decirlo, a los títulos y demarcaciones de propiedad privada), pero que no es por eso menos real e importante en la experiencia cotidiana y desde el punto de vista del análisis antropológico? ¿Cuáles son las percepciones territoriales locales y a qué nociones de justicia van aparejadas? ${ }^{11}$ ¿Cómo abordar este tema en un oasis como San Pedro de Atacama, donde el mercado de la tierra se ha transformado de modo tal, que algunas viejas chacras de alfalfa han multiplicado en más de cien veces su valor comercial en los últimos 10 años, con la consecuente marginación del campesinado más pobre? ¿En qué instituciones territoriales o cuáles (geo)artefactos o símbolos distintivos se apoyaría una eventual personalidad territorial atacameña? ¿En qué difieren las interacciones territoriales entre los que son nativos (nacidos y criados) de la zona y aquellas que se desarrollan conforme al sistema de circulación de la propiedad inaugurado por las decimonónicas leyes de la República, con sus títulos y registros? ¿Qué implicancias territoriales e identitarias podrían resultar del actual proceso de saneamiento de la propiedad atacameña? Resumiendo, y más allá

11 X. Albó recordaba que las demandas más básicas de los de la zona de Jesús de Machaqa (Bolivia) invariablemente se condensaban en "tierra y justicia" (com. pers. 2003). de la titulación a ejecutarse en nombre de la Ley Indígena, ¿cuáles son las sensibilidades territoriales en juego?

A este raudal de preguntas se añaden confusiones, como la del líder cocalero y diputado boliviano Evo Morales, cuando afirmaba, refiriéndose a nuestra zona de estudio: "Esos territorios no son chilenos, esos territorios son aymaras, y esos territorios aymaras son de los bolivianos" (Teletrece 4/1/2004). ${ }^{12}$ ¿De qué está hablando? ¿Qué está ocurriendo? En momentos en que el reclamo por un acceso soberano a las costas del Pacífico de parte del gobierno boliviano (enero de 2004) vuelve a cobrar cierta actualidad mediática en el plano latinoamericano (con diversos estadistas agitando y aventándose títulos históricos coloniales y postcoloniales), llama la atención de que nadie salvo Evo Morales haya reflexionado respecto de las tierras que eran posesión y propiedad de los "indios originarios" diseminados por las extensiones puneñas fueran de la República de Bolivia. A mi juicio, las circunstancias que han llevado, reiteradamente, a expresiones identitarias y territoriales excluyentes como las pintarrajeadas por los etnopandilleros de nuestro presente etnográfico (o las de Evo Morales, e incluso las del gobierno chileno) refuerzan que el problema de los límites se mantiene como uno de los desafíos intelectuales y teóricos más presentes en la antropología de la región.

Suponiendo cierta continuidad territorial o cadena de transmisión propietaria entre los de hoy y los de ayer, ¿cuál es la historia de los ahora "ciudadanos étnicos" chilenos que antes estuvieron adscritos a Bolivia y Perú, a la Audiencia de Charcas y al Virreinato? De alguna manera, las territorialidades y las identidades transpiran de las

\footnotetext{
12 Ningún personero del gobierno chileno se hizo cargo del supuesto trasfondo étnico levantado por Morales. Sólo el senador Núñez (actual Presidente de la Comisión de Relaciones Exteriores del Senado), en una entrevista conjunta con el ex canciller del gobierno militar, Hernán Felipe Errázuriz (quien no se inmutó), declaró que el tema con Bolivia se complicaba con la presencia aymara en las regiones primera y segunda de Chile (Telenoche 5/1/2004). La mayoría -por no decir casi toda- de la población aymara que hoy vive en Chile se encuentra más bien repartida por la primera región (ex territorios peruanos). Si se insiste en hablar en términos étnicos, de la actual II Región se podría decir que es territorio "atacameño", etnia precisamente distinta de la aymara.
} 
crónicas estatales sobre los diferendos limítrofes que reventaron entre los países sudamericanos a lo largo del siglo XIX, una de las "corridas de cercos" más significativas de la historia chilena. La breve reseña de los principios y antecedentes jurídicos que incidieron en los procesos históricos de titulación de los Andes centro-sur, tal vez nos ayude a esclarecer, a continuación las relaciones que hemos venido esbozando entre procesos identitarios y propietarios.

\section{Atacama colonial y postcolonial: Los límites pendientes}

a) Burocracia imperial, costumbre medieval y títulos verbales de tiempo inmemorial

Sabemos que la corona española reconocía la plena validez de la propiedad preexistente o de "posesión inmemorial" de los indígenas. La "Instrucción que dio el Virrey don García de Mendoza a los Comisarios de Tierras" ordenaba explícitamente:

"Que los indios que poseyeren tierras o heredades suyas propias, o las hubieren heredado de sus padres, o otros de quien pudieran heredarlas, o que se las dieron, y repartieron en visita general, o que las hayan comprado de cualesquier personas, o dádoselas cuyas eran, y las poseían con títulos legítimos, o en propiedad, que estas tales tierras no se quiten, ni sean quitadas a los Caciques, ni Indios que las tuvieren, e poseyeren; antes sean amparados en ellas por los dichos Comisarios, e Jueces y se las confirmen de nuevo, y por la dicha confirmación no se les ha de llevar cosa alguna, ora sea en mucha, o en poca cantidad las dichas tierras",

agregando que

"no han de ser compelidos los dichos Indios a mostrar títulos, porque entre ellos no los tienen, sino que verbalmente los Comisarios, y Juezes de tierras se informen de oficio, que tanto ha que posee el tal Indio las tierras que tiene, y si las heredó de sus padres, y abuelos, o en que forma las posee, de manera que conste ser legítimo poseedor dellas, y que no las ha usurpado: y el Juez, y Comisario ha de dar sumariamente en la relación de lo que hicieren, para que yo les dé confirmación, las causas y razones que hubo para se las dar, y confirmar; o para se las quitar" (Escalona Agüero 1647, II: 208; énfasis es nuestro).

Para cualquier estudioso del régimen propietario indiano queda claro que el aforismo del "se acata, pero no se cumple" fue particularmente duro con los indios. Exactamente 50 años después de la citada instrucción, de España volvían a insistir que: "a los dichos indios se les dejen con sobra todas las [tierras] que le pertenecieren, así en particular como por comunidades..." (Escalona Agüero 1647 , II: 212 ; énfasis es nuestro). Los funcionarios de la Corona que establecían y controlaban los mecanismos burocráticos de verificación de las relaciones entre las personas y sus propiedades estaban tan conscientes del predicamento étnico, que se requirió, además, que cualquier composición de tierras con indígenas pasara por un informe del Protector General de los mismos. ${ }^{13}$ Con excepción de unos pocos amparos reales en beneficio de algunos caciques de la primera región (documentos cuya veracidad interna aún queda por demostrarse), no se ha encontrado todavía el pleno equivalente de los llamados "títulos primordiales" mexicanos para las regiones I y II de Chile, y casi ninguna composición (en boga a mediados del siglo XVII) o confirmación (s. XVIII). ${ }^{14}$ El no haber hallado tales títulos tal vez se deba a los cambios en la propia legislación colonial, que alguna vez estableció que los títulos sólo podían ser validados por el rey, otras por el virrey, o alguna Audiencia. Es posible que algunos papeles referentes a las propiedades de los pueblos adscritos a la Audiencia de Charcas estén en algún archivo limeño. También puede que, por su lejanía y su pobreza, tales documentos nunca hayan sido emitidos para la zona que nos ocupa, o que adoptaran la forma de documentos sui generis como el acta que hizo levantar el corregidor Juan Velázquez de Altamirano con ocasión de haber traído de paz a "los indios de Atacama", cuando

"les mostró mucho amor y voluntad y les hizo buen tratamiento dandoles ropas de brocado y çeda y muçhos cestos de coca y otras muçhas cosas de

13 Véase por ejemplo, para Chile, el informe jurídico reseñado por Almeyda (1940).

14 Para una cronología de los sucesivos cambios en el régimen de titulación administrativo colonial de las tierras indígenas, véase Solano (1984). 
su traer en señal de amor y les dió a entender [a los caciques allí reunidos] que debaxo de ser cristianos y basallos de su magestad serían amparados e tenidos en justicia e ternan sosiego en sus tierras" (AGI Patronato $188 \mathrm{n}^{\circ}$ 4, 4 fs; documento transcrito por J. L. Martínez 1992; énfasis es nuestro). ${ }^{15}$

En efecto, y salvo algunos casos excepcionales (p.e., "indios bravos" como los mapuche en Chile, y los Chichimeca y los Mixe en México), el régimen territorial colonial se caracterizó por ser intrínsecamente mediado y negociado por caciques. La burocracia colonial no buscó delimitar geográficamente la propiedad indígena sino cuando surgían problemas puntuales; por lo general, dejó la resolución de los pleitos indígenas por límites a la costumbre, con apoyo de los traductores y juristas expertos capaces de desentrañar la sensibilidad jurídica local, caso a caso (Ots Capdequi 1959; Rivera Marín 1983). Como ya se anticipara, y tal como ocurrió en otras partes de América Latina, en ocasiones la territorialidad local se confundió con la extensión del poder personal del cacique. Puede que los títulos o amparos de tierras andinos extendidos (y a veces falsificados) en favor de, por ejemplo, el cacique Chuquichambe de Chiapa (Hidalgo 1986; Gundermann 2003), hayan constituido reconocimientos administrativos (no propietarios) de la jurisdicción fiscal de los mismos, de su "cacicazgo" o "curacazgo". Por otra parte, en las tierras altas de Arica y Tarapacá la relación entre tales cacicazgos podía implicar, según Hidalgo, "un sistema de jurisdicciones territoriales compartidas" (cit. en Gundermann 2003). En todo caso, el proceso de amojonamiento colonial a que se refiere Gundermann parece cristalizar momentos y zonas de tensiones y conflictos entre comunidades, más que "jurisdicciones discretas". Que la Corona nunca intentara levantar un "catastro general de todas las tierras" refleja la importancia de la relación personal con los indios, propia al siste-

\footnotetext{
15 Documentos o "arreglos constructivos" como el citado establecen el dominio indígena preexistente y se asemejan a un tratado. Se puede sostener que, por lo menos hasta el momento de levantarse esta acta española (y suponiendo que lo que dice es cierto), los caciques no reconocían a la Corona, y por lo tanto mantenían su calidad de sujetos de derecho conforme al jus gentium o "derecho de gentes" reconocido en la época (precursor del actual derecho internacional). Véase M. A. Martínez (1999).
}

ma medieval de vasallaje, casuismo y fueros. A la Corona no le interesaba realmente definir ni medir territorialmente a los indígenas, sino más bien su cantidad, para efectos tributarios. No parece claro, por lo tanto, que el sistema colonial en los Andes se desplegara efectivamente con fronteras territoriales realmente duras. Las fronteras parecen haber sido duras tan sólo en el papel, y a través de sanciones aplicadas a los desafortunados transgresores que fueran capturados (SánchezAlbornoz 1978); es más, sólo se entiende una política de fronteras duras cuando el movimiento transfronterizo es casi incontenible. Decir que había "presiones sobre las fronteras" oscurecería la micropolítica transfronteriza y su correspondiente juego de territorialidades. ${ }^{16}$ La ley - o frontera literal- es una pequeña valla en comparación con las dificultades del altiplano, del desierto y de la miseria. Las fronteras eran más bien fiscales.

\section{b) La época boliviana: El Estado expoliador}

Los habitantes del Desierto de Atacama han mantenido formas de posesión y concepciones de lo propio y de lo ajeno que todavía intrigan a los antropólogos por su complejidad y que no podían menos que ser distintas de aquellas que la legalidad colonial acostumbraba reconocer (pueblos, fundos, dehesas, ejidos). Tras la Independencia ¿cuál fue el estatus jurídico de los antiguos "títulos verbales" atacamas que ampararon las leyes de Indias? ¿Reconoció la propiedad indígena la República de Bolivia? Por su cercanía a los eventos, Sotomayor resulta doblemente elocuente:

"Algunos hombres de estado pensaron... desde las campañas de la independencia del Perú, preparar la rejeneración de la raza indígena hasta incorporarla, como un elemento vivo y fecundo, en el nuevo sistema de vida política y social enjendrado por la independencia. Comprendiendo que para llegar a este fin sería conveniente dignificar al indio con el derecho de propiedad territorial, y estimularle al trabajo y a la adquisición de nuevos goces sociales, el Libertador Simón Bolivar dictó en Trujillo el decreto de 8 de abril de 1824, en el cual dispuso que las tierras de comunidad pasasen al pleno dominio de sus actuales poseedores. Poco después [en 1825] en el Cuzco el mismo Libertador.. lo modificó y reglamentó... [ordenando] que la adjudicación de

\footnotetext{
16 Véase Alvarez (1995), en el mismo sentido.
} 
tierras en propiedad debía hacerse a razón de un topo [aprox. $1700 \mathrm{~m}^{2}$ ] por cada indígena en los lugares pingües y regados, $i$ de dos topos en los estériles o sin riego, añadiendo la prohibición de enajenar estas tierras hasta 1850" (1874: 302).

Una nueva ley dictada el año siguiente suspendió la ejecución de este decreto mientras no se censara y catastrara a los indígenas y las tierras sin ocupación. La ley de 25 de octubre de 1831 declaró en favor de los indígenas la absoluta propiedad de los terrenos poseídos por ellos durante más de 10 años, facultando al Mariscal Santa Cruz para dictar los reglamentos de ejecución. Según Sotomayor, el Mariscal,

"sin poder ocultar el tinte de su sangre indígena, pretendía hacerse el representante más caracterizado de la raza india, no creyó oportuno poner por obra esa ley, y en 1838, prohibió terminantemente la enajenación de los terrenos reconocidos por la ley de 1831, declarando nulas las transacciones que se hubiesen celebrado en virtud de ella" (Sotomayor 1874: 303). ${ }^{17}$

Como sea, no volvió a tratarse legalmente la materia hasta 1842 , cuando el presidente general Ballivián, por una simple circular de 14 de diciembre, declaró ser de propiedad del Estado todos los terrenos poseídos por indios, considerando a estos últimos como enfiteutas y obligados, por tanto, a continuar pagando una contribución al Estado. Raimondi señala que, por esa misma época (y tal vez en relación con el decreto de Ballivián), "los Indios de las provincias Bolivianas de Llica, Lipes y Atacama" usurparon tierras peruanas (Raimondi 1879: 86).

Luego, mientras Melgarejo renunciaba a las más insignes pretensiones territoriales de Bolivia (moteando los límites con los países vecinos de meras "líneas matemáticas"), empezó a escasear el dinero público boliviano. Daireaux evoca cómo, hacia 1866 ,

“todo lo había ensayado Melgarejo, y todos los manantiales [de dinero] se habían agotado. Era preciso inventar algo nuevo [para conseguir dine-

17 Según Ruiz-Tagle, Santa Cruz era "nieto del Cacique Calaumana, y sostenía ser heredero directo de la dinastía de los incas y así lo sostuvo públicamente durante su Gobierno. En realidad era de origen aimará [sic]" (1992: 9). ro], y una idea, que ni la embriaguez misma (fuente habitual de su inspiración) hubiera hecho nacer en el cerebro de Melgarejo, le fue sugerida por sus Ministros. Se trataba de confiscar y vender a beneficio del estado, las enormes extensiones de terreno que los indios poseían en común, en virtud de un derecho ancestral inscrito en los Códigos Incaicos que siempre habían respetado los conquistadores y que Bolivar había reconocido y confirmado en repetidas ocasiones. Atentar contra este derecho era un delito criminal, pero Melgarejo aceptó la sugerencia de sus Ministros sin medir las consecuencias. Una vez terminadas las ventas no les quedó nada más que hacer a los nuevos propietarios que apoderarse de sus bienes. Pero los indios se opusieron a la expoliación y fueron los principales interesados, los generales Antezana y José Aurelio Sánchez, recientemente ascendido, los que tuvieron el "honor" de someter a esos insurrectos que solamente poseían hondas y palos para defenderse... Había que ver.. las grandes hazaña [sic] que llevaron a cabo aquellos capitanes. Sus soldados se apoderaban de los adolescentes y los amarraban desnudos a postes de madera para tirar al blanco con sus flechas en presencia de los padres de los desventurados. Los soldados se hastiaban de violar doncellas hasta que el contacto de la sangre pegajosa les daba náuseas. Los jinetes amarraban los caciques a la cola de sus caballos que hacían correr al galope, abonando así las tierras robadas con la sangre de sus legítimos propietarios" (1963: 195-197). ${ }^{18}$

Tal aplicación de estas normas confiscatorias casi desata una nueva guerra entre el Perú y Bolivia:

"El origen de estas desaveniencias fue una incursión hecha en territorio peruano por el jeneral Antezana [primo de Melgarejo] al frente de tropa armada. Dicho jeneral había sido mandado a escarmentar a algunos indios descontentos por la parte de la frontera del Perú. Persiguiéndolos con encarnizamiento pasó la raya fronteriza i llegó hasta el punto llamado Huancané donde la tropa hizo destrozos, incendiando, saqueando i matando. Al regresar la fuerza espedicionaria, se trajo cautivos algunos indios de corta edad, que según me aseguran, han sido vendidos en La Paz [Oficio ${ }^{\circ}$ 95, de 17 de mayo de 1870]" (Sotomayor 1912: 326-327).

18 Antezana habría adquirido 300.000 has magníficas a orillas del Titicaca (Ruiz-Tagle 1992: 196). 
Antezana ya tenía ganada su reputación de "maestro en bajezas". Daireaux ilustra la verdadera guerra de exterminio que el general sostuvo contra los indios en razón de su famoso "decreto de expropiación".

"Si la primera campaña de Antezana había sido atroz, ésta la superó en horror. Quemando los poblados, degollando las mujeres, los niños y los viejos, hostigó a los indios, hordas estúpidas, que no pudiendo defenderse se refugiaron en el Perú. ¡Antezana les persiguió! Un funcionario peruano trató de detenerle, explicándole que violaba la frontera, pero le dio muerte por su propia mano. A otro que se presentó, le hizo cortar la lengua "para que no profiriese más insolencias estúpidas" y amarrándole a la cola de su caballo le "invitó a que lo acompañara en su campaña”... Para escapar a la masacre, las poblaciones fronterizas abandonaron sus casas que fueron quemadas, dándose orden a los soldados de "tirar sobre cualquiera que tratase de extinguir un incendio". Cuando las tropas de Antezana, hartas por fin de matanzas, violaciones e incendios, se retiraron, llevaron consigo todo el ganado que pudieron encontrar, los indígenas jóvenes reducidos a la esclavitud..." (Daireaux 1963: 200-201).

En su protesta formal ante el gobierno de Melgarejo, el legado peruano describe los hechos, que

"son a tal punto abominables que parece increíble que se hayan producido en nuestra época pues solamente volviéndose a la historia de la edad media, cuando los bárbaros invadieron Roma [sic], podrían encontrarse hechos parecidos, ya que su paso quedaba marcado por la desolación, la ruina y la muerte" (Daireaux 1963: 200-201).

Sotomayor informa desde Cochabamba que, en respuesta a este agravio:

“el Gobierno del Perú continúa reuniendo fuerzas en Arequipa, Tacna i Puno [Oficio ${ }^{\circ}$ 92, de 25 de abril de 1870]" y algunos días después, que éste

“continúa moviendo su ejército hacia la frontera y acumulando formidables elementos de guerra. Si, como se asegura, la situación del presidente Balta se ha vuelto azarosa i difícil en el Perú, no sería estraño que estuviese resuelto a hacer una guerra esterior, como un recurso de política interior. Además, los pueblos peruanos más próximos a la frontera de Bolivia desean la guerra" [Oficio $\mathrm{n}^{\circ}$ 93, de $1^{\circ}$ de mayo de 1870] (Sotomayor 1912: 302-305; énfasis es nuestro).

A todo esto, los límites seguían siendo un rompecabezas para los respectivos gobiernos, al punto que se refiere que cuando Melgarejo le encaró a su general el incidente fronterizo con Perú, éste habría respondido: “¡Pero, os juro Excelencia, que jamás he franqueado la frontera del Perú! ¡Qué diablo!, si tal cosa existiese, yo la hubiera visto y podría deciros como es" (Daireaux 1963: 202).

En 1874, bajo el gobierno del presidente Frías, se pusieron otra vez en ejecución los decretos de mensura de Bolívar mediante la Ley de Exvinculación de Tierras. Aunque esta ley desconoció la existencia jurídica de las comunidades y ayllus, reconoció la legalidad de los títulos entregados a los indígenas y estableció que las tierras que no estuvieran en su posesión fueran declaradas sobrantes y propiedad del Estado. Se inició una "Revisita General" en todas las provincias que tenían "tierras de origen" con el propósito de: a) otorgar títulos de propiedad a los indígenas originarios, forasteros y agregados que poseían tierras bajo mojones y linderos conocidos; ${ }^{19}$ b) reconocer la posesión en común sobre pastizales, abrevaderos y bosques y; c) declarar tierras sobrantes y, por ende, pertenecientes al Estado todas aquellas que no se hallaban en posesión de indígenas. Estas medidas no parecen haber alcanzado a Atacama. Para el caso que analizamos, empero, lo que importa es que es imposible que las propiedades atacameñas se registraran en Bolivia antes de la guerra del Pacífico, y esto, simplemente, porque no existió un sistema conservatorio como el chileno en ese país, sino hasta la promulgación de la Ley de Inscripción de Derechos Reales de 15 de noviembre de 1887 (que inauguró el sistema registral único y público de Bolivia). ${ }^{20}$

19 Sotomayor (1874: 526) detalla algunas de estas categorías fiscales, tal como fueran establecidas por la Audiencia de Charcas, las que se mantuvieron bien entrada la época republicana: indios originarios, indios agregados con tierras, mitayos, indios forasteros sin tierras o vagos (también conocidos como yanaconas). Estos últimos se subdistinguían entre los "yanaconas de chacra" y los "yanaconas de la Real Corona" (los que tras la independencia se llamarían "yanaconas del Estado").

20 El Reglamento del Registro Conservatorio de Bienes Raíces chileno se había promulgado en 1857. 
Es obvio, entonces, que la falta de inscripción no implicaba que los indígenas no tuvieran propiedad, y se puede ver que el tema de la propiedad indígena no dejó de animar los debates y conflictos de la joven república boliviana, tanto interiores como exteriores, y hasta bien entrado el siglo de la independencia. El hecho es que tal "problema indígena" no se había zanjado al estallar la guerra del Pacífico. Tras ella, sin embargo, y a diferencia de lo que había venido ocurriendo en otros países latinoamericanos, los agentes territoriales del fisco chileno estimaron que al advenir la soberanía chilena "caducaron" las propiedades indígenas. Veremos cómo, al actuar de esta manera, se fue claramente en contra del texto y el espíritu del Tratado de Paz y Amistad celebrado con Bolivia en 1904, y de los principios básicos del derecho internacional en lo concerniente a lo que sucede respecto de la propiedad privada al producirse una sucesión entre Estados. Ultimamente, se ha ido incluso en contra de la propia Ley Indígena chilena, dictada precisamente para reparar los supuestos olvidos anteriores.

\section{c) La época chilena: El Estado usurpador}

\section{"Serán reconocidos por la Altas Partes Contra- tantes los derechos privados de los nacionales o extranjeros que hubieren sido legalmente adqui- ridos, en los territorios que, en virtud de este Tra- tado, quedan bajo la soberanía de uno u otro país" (Tratado de Paz, Amistad y Comercio celebrado con Bolivia en Santiago el 20 de octubre de 1904, Artículo II, inciso 21). ${ }^{21}$}

De conformidad al mencionado tratado y a los principios básicos del derecho internacional, el Estado-fisco chileno no se hizo, ni pudo hacerse dueño particular de las tierras atacameñas por el solo hecho de anexarse el territorio del litoral boliviano (Figura 2). ${ }^{22}$ Tanto así, que se hizo va-

21 El Artículo $7^{\circ}$ del Tratado de Lima de 1929 estableció una obligación recíproca similar: "Los gobiernos de Chile y del Perú respetarán los derechos privados legalmente adquiridos en los territorios que quedan bajo sus respectivas soberanías".

22 En 1924, la Corte Permanente de Justicia Internacional (CPJI) sentó definitivamente el principio de que "los derechos privados adquiridos conforme a un derecho en vigor no incurren en caducidad como consecuencia de un cambio de soberanía. No puede pretenderse que los derechos privados adquiridos conforme a [una legislación válida antes del cambio de soberanía] estén condenados a extinguirse. Una tal pretensión no está basada en ningún principio y ler la soberanía del Estado en el ámbito de las relaciones propietarias mediante una inscripción de dominio sobre las tierras sobrantes, baldías o desocupadas que pudieran identificarse. ${ }^{23}$ Inició el proceso como cualquier particular, haciendo solicitudes y publicando anuncios en "La Verdad" de Calama. Tres títulos "de mayor cabida" inscritos en el Registro Conservador de Bienes Raíces le permiten al fisco darse por dueño de las superficies correspondientes a las actuales Municipalidades de Ollagüe, Calama y San Pedro de Atacama, y venderlas. ${ }^{24}$ Ahora bien, legalmente, esta inscripción fiscal, por carecer de objeto determinado, sólo debe entenderse que vale sin perjuicio de los derechos de propiedad que cualquiera -incluyendo los indígenas- pudiera hacer valer. ${ }^{25}$ Dougnac (1975) sostuvo incluso que, mientras no se dictara en Chile una ley especial que incluyera a los indígenas del norte del país (como la de 1993), seguían vigentes las normas establecidas en la Recopilación de Leyes de Indias. Hasta 1993, sin embargo, ninguna ley tomó seriamente en cuenta la legítima propiedad ancestral de los indígenas asentados en los territorios anexados. ${ }^{26}$

sería contraria a la opinión y a la práctica cuasi-universal" (CPJI, Serie B, nº 6, p. 36). En el mismo sentido se expresó el Tribunal en su Sentencia de 25 de mayo de 1926 relativa a los Intereses alemanes en la Alta Silesia polaca (Diez de Velasco 1983: 228). Agradezco al abogado e historiador José Miguel Barros por esta referencia.

23 El Artículo 590 del Código Civil chileno señala que "Son bienes del Estado todas las tierras que, estando situadas dentro de los límites territoriales, carecen de otro dueño" (énfasis es nuestro). A éstos, la ley también les llama "bienes fiscales".

24 El artículo 730 del Código Civil chileno define claramente la noción de usurpación que empleamos. "Si el que tiene la cosa en lugar y a nombre de otro, la usurpa dándose por dueño de ella, no se pierde por una parte la posesión ni se adquiere por otra; a menos que el usurpador enajene a su propio nombre la cosa. En este caso la persona a quien se enajena adquiere la posesión de la cosa, y pone fin a la posesión anterior" (énfasis es nuestro).

25 El argumento jurídico es como sigue: aquel año de 1933, el Estado no pudo inscribir como tierras fiscales más de lo que legítimamente podía, es decir, solamente aquellas que no tuvieran dueño. Como al momento de la anexión no había sistema de registro público de la propiedad en Bolivia, era imposible que la "propiedad" atacameña estuviera inscrita ni podía estarlo.

26 Tras la guerra, y a diferencia de lo ocurrido con las propiedades indígenas, los señores Alsop y Cía., Juan Meiggs y Juan Garday vieron explícitamente reconocidas sus propiedades conforme al artículo V del ya citado Tratado de Paz y Amistad. Las propiedades de las corporaciones jurídicas que tantas veces habían sido amparadas por la Corona española no tuvieran la misma suerte. 


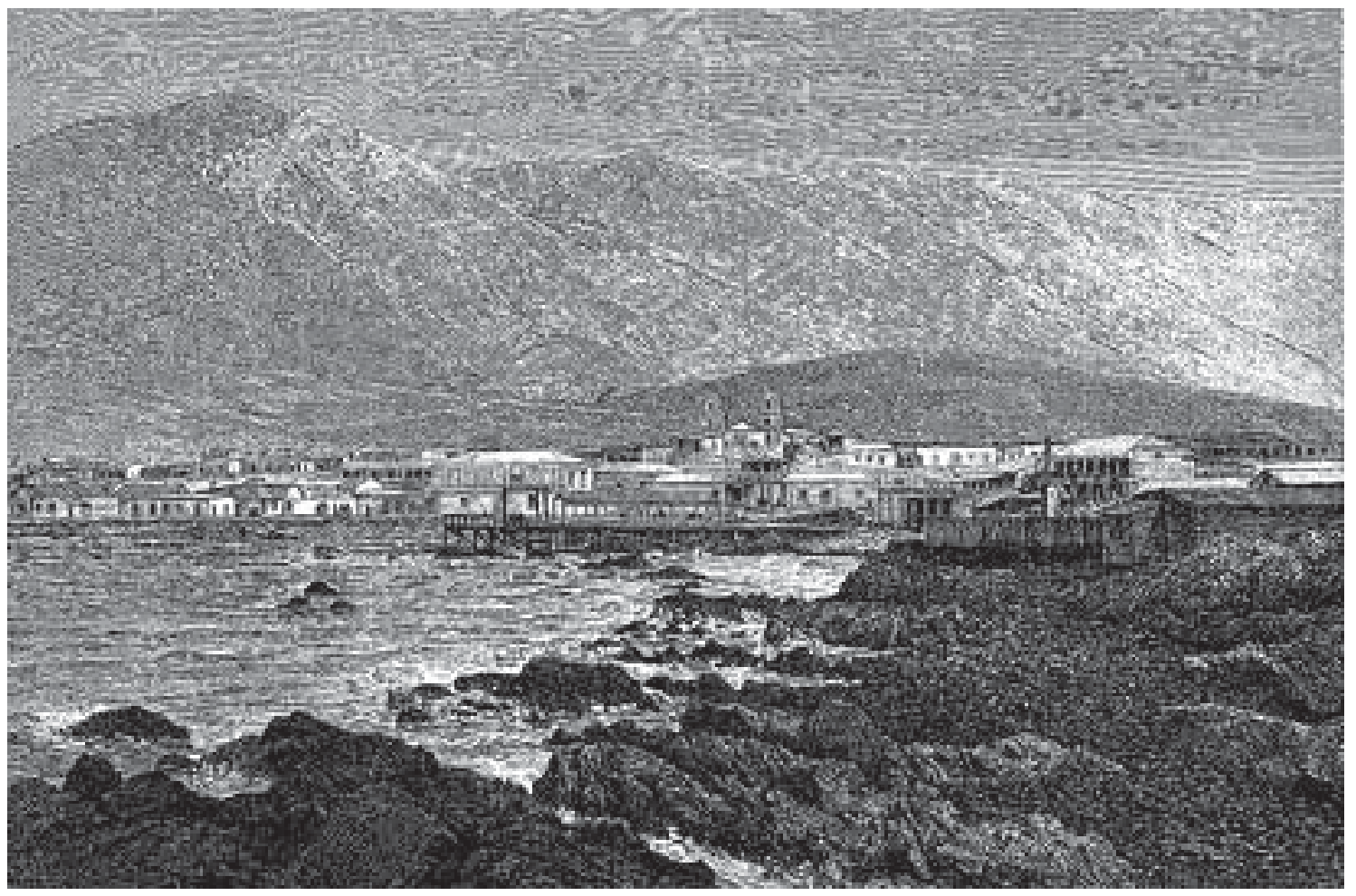

Figura 2. Grabado del puerto de Cobija en 1874. Dibujo de Taylor basado en una fotografía. Colección particular.

En todo caso, se puede afirmar una cosa fuera de dudas: no se ha cumplido la predicción que hizo Andrés Bello en el preámbulo de su Código Civil. Allí sostuvo que algún día se lograría la "plena inscripción" de la propiedad raíz en Chile. El genial plan iba así: a partir de la promulgación del Código Civil, cualquier venta de tierras, para ser reconocida por la justicia, requeriría de la previa inscripción del título de compraventa en el registro conservador de bienes raíces. Igual requisito de la inscripción se exigió para vender bienes inmuebles que formaban parte de una herencia. Suponía Bello que algún día no muy lejano, con la natural circulación de los bienes (nadie se salva de la muerte), todas las propiedades particulares en poder de personas naturales terminarían por estar inscritas, sin más, de un modo casi automático. De este panorama optimista, Bello tan solo exceptuó explícitamente a las personas jurídicas (como corporaciones, fundaciones, compañías): entre éstas, y aunque tardíamente reconocidas por la actual Ley Indígena, caben las comunidades atacameñas.

Aunque tal vez sin conocer las cavilaciones de Bello, pero sin duda que por el mismo vacío jurí- dico que él anticipó (y que se hizo aún más hondo respecto de las propiedades que quedaron en el territorio anexado a Bolivia), en 1993 el Estado chileno se obligó a:

"salvaguardar los siguientes tipos de dominio aymara y atacameño: a) Tierras de propiedad de indígenas individualmente considerados, que por lo general comprenden la casa habitación y terrenos de cultivo y forrajes; b) Tierras propiedad de la Comunidad Indígena constituida en conformidad con esta ley y correspondientes, por lo general, a pampas y laderas de cultivo rotativas. c) Tierras patrimoniales de propiedad de varias Comunidades Indígenas, tales como pastizales, bofedales, cerros, vegas y otras de uso del ganado auquénido...".

El artículo $3^{\circ}$ transitorio de dicho cuerpo legal fijó, además, el plazo perentorio de tres años posteriores a la publicación de la ley para que la CONADI y el Ministerio de Bienes Nacionales (administrador de la propiedad fiscal inscrita en 1933) realicen un plan de saneamiento de títulos de dominio sobre las tierras arriba mencionadas. $\mathrm{O}$ sea que 
para el 5 de octubre de 1996 a más tardar, se debiera haber realizado el saneamiento: van 10 años desde la promulgación de la ley, y todavía no se cumple.

Es importante recalcar que el texto de la ley chilena sí reconoce la subsistencia de formas propietarias indígenas preexistentes, no-inscritas, consuetudinarias, de proximidad o subyacentes. Sostengo - esta vez como abogado- que éstas no se han extinguido legalmente en Atacama ni se han podido extinguir. ${ }^{27}$ Por definición, las tierras patrimoniales del conjunto de comunidades atacameñas serían aquellas que, poniéndose en el caso de la excepción de Bello, son tierras de personas jurídicas que nunca fueron inscritas porque nunca se transfirieron por venta, ni se han inscrito como herencia, como ocurre, en algún momento $\mathrm{u}$ otro, con las propiedades de las personas naturales. El que nunca se inscribieran no impide que de conformidad a la costumbre y a las leyes bolivianas hayan sido formas plenas de dominio corporativo. Es más, la Ley Indígena chilena reconoce (no "constituye") a las comunidades indígenas, o sea que considera que en tanto comunidades sociológicas, éstas ya eran sujetos pasivos de derechos (p.e., con capacidad de goce), pero que hasta entonces habían carecido de personalidad jurídica (p.e., sin capacidad de ejercicio), lo que les impedía ser sujetos activos en la representación de sus derechos corporativos. Para todos los efectos, las comunidades indígenas que han sido reconocidas por la ley gozaban de todos los derechos anteriormente respetados por la Corona, incluyendo las propiedades que luego serían incluso reconocidas por el rosario de tiranuelos bolivianos --aunque tan solo fuera para mejor liquidarlas. ${ }^{28} \mathrm{El}$ punto es que, al hablar la Ley Indígena de "salvaguardar la propiedad indígena sobre las tierras patrimoniales", obviamente que habla de tierras que no han sido ni pudieron haber sido inscritas antes de la Ley Indígena. Aunque pudieron haberlo deseado, las comunidades, como tales ¡carecían de la categoría y habilitación jurídica necesaria para hacerlo! No es preciso entrar en disquisiciones leguleyas, pero no cabe interpretar

27 Para las nociones de títulos "consuetudinarios" subyacentes y de proximidad, véase Sutton (1996) y Barros (2003).

28 Un proceso similar ocurrió en México bajo la dictadura liberal de Porfirio Díaz (fines del s. XIX), donde incluso llegaron a traficarse los títulos coloniales que permitían saber qué tierras eran indígenas y podían rematarse y cuáles no por ser fiscales o baldías. la Ley Indígena en otro sentido que el expuesto: si ha de tener algún efecto (y se supone que es para eso que se dictan leyes), no puede entenderse que al hablar de "salvaguardar", la ley se estuviera refiriendo exclusivamente a la propiedad inscrita (como lo han venido interpretando los funcionarios del Ministerio de Bienes Nacionales). En efecto, estando inscrita, la propiedad, como tal, no requiere de salvaguarda adicional.

Por lo demás, el artículo de la ley que hemos citado es meramente enunciativo respecto de cada una de las formas de propiedad indígena que menciona. Al no ser taxativa, la ley dejó claramente abierta la posibilidad de que existieran otras formas y objetos de propiedad que los que se mencionan allí a título de ejemplo. Es más, la ley ordenó se efectuara un catastro de las tierras precisamente porque el legislador chileno no fijó criterios particulares para identificar las tierras patrimoniales atacameñas, dejando pendiente la tarea de su definición.

El 27 de agosto de 1996, el entonces Jefe del Catastro Nacional de los Bienes del Estado hizo entrega del Informe de Avance $\mathrm{n}^{\circ} 1$ del Proyecto Ordenamiento Catastral de las Comunidades Indígenas del Altiplano de la II Región. Profesionales contratados por el Ministerio de Bienes Nacionales (MBN) identificaron la "demanda territorial” atacameña, la que llegó a sumar cerca de 3.000.000 has (MBN-CINPRO, 1996). ${ }^{29}$ Uno podría suponer, razonablemente, que junto a esta información recabada por expertos, las declaraciones y demandas territoriales manifestadas por las comunidades indígenas habrían bastado para la declaratoria de propiedad indígena en los términos señalados por la ley. ${ }^{30} \mathrm{El} \mathrm{MBN}$, desgraciadamente, terminó por rechazar las demandas formuladas por las autoridades étnicas, así como la superficie informada por los peritos contratados al efecto: los agentes ministeriales opusieron e impusieron, unilateralmente y sin apelación, el criterio de la "posesión actual y material" que los

29 Quedaron fuera de esa etapa del catastro las superficies correspondientes a las comunidades atacameñas de San Pedro de Atacama, Coyo y Quitor.

30 Por "demanda territorial" atacameña, CINPRO, la consultora que ejecutó el estudio en su primera fase se refería originalmente a las tierras "de uso actual y ancestral identificadas a partir de un análisis antropológico, histórico, sociológico y arqueológico, basado en trabajo en terreno" (MBNCINPRO 1996). 
indígenas pudieran tener de las tierras en cuestión (incluso se llegó seriamente a hablar de entregar una hectárea por llama). Según me lo explicara luego uno de los encargados del tema, reconocer tal extensión habría "atentado contra el desarrollo del país". Sin saberlo, repitió casi en los mismos términos los dichos de un funcionario boliviano que, corriendo la década de 1860 , señalaba "no es posible dejar inmensos territorios en manos de los indios que son incapaces de hacerles producir" (cita en Daireaux 1963).

De modo que, para 1998, las hectáreas a regularizar ya habían disminuido a 1.874.868,46 (Muñoz 1999: 34). Hubiera sido interesante que, en su estudio, Muñoz hubiera dado un total para la demanda territorial indígena, cuantificando la diferencia con la tierra identificada como "territorio con potencial agropecuario" (1.349.324,35 has). Esto hubiera permitido ensayar una explicación: en una nota al pie insinúa que uno de los argumentos para desestimar la demanda étnica es que los encuestados "reclamaron [tierra] sin aducir título [escrito] alguno a nombre propio o de terceros, y tampoco se reconoció una efectiva posesión material" (Muñoz 1999: 34). Según me han afirmado los antropólogos que trabajaron en el catastro inicial, los agentes fiscales optaron por el reconocimiento a priori de la propiedad fiscal y sus límites englobantes municipales y estatales, para luego empezar a constituir (a partir del título fiscal) una serie de "concesiones de uso" sobre "anillos de protección" en torno a los ayllus, y algunos "polígonos" en áreas de vegas y bofedales. Actualmente (2004) y a pesar de no reconocer otra propiedad que la inscrita, el Estado ya habría transferido, bajo las modalidades señaladas, más de 400000 has de un total aproximado de 900000 identificadas en el catastro final. Los agentes del MNB se desentendieron del "dominio atacameño" que la ley les exigió salvaguardar y, como consecuencia, las comunidades no serían propiamente dueñas de toda la tierra concedida: gran parte de las mismas quedaría fuera del marco de protección de la Ley Indígena.

Al igual que en la primera región, los límites tradicionales entre pueblos y comunidades que han manifestado los dirigentes indígenas no han sido reconocidos. ${ }^{31}$ El MBN descartó de plano la vi-

31 El caso del agua ha tenido un desarrollo diferente, porque los tribunales han reconocido el dominio preexistente o "posesión regular de tiempo inmemorial" de las comunida- sión y los conocimientos territoriales locales y regionales, rechazando los repertorios autóctonos de dominio anteriores al Estado. Apartándose de las demandas territoriales indígenas, aisló lo que consideró ser la posesión "material y efectiva" de los atacameños sobre la base de interpretaciones técnicas suplementarias. Así, el catastro oficial de las tierras y patrones de ocupación atacameños se volvió claramente arbitrario e ilegal. La retórica propietaria resultante de todo este proceso ha fortalecido el poder del Estado en la medida que "el problema indígena" generado ha rendido beneficios políticos para los que se han convertido en las nuevas élites (internas y externas, indígenas y no indígenas) de "lo atacameño". Los excluidos de esta etnopolítica de subsidios y denegaciones generan luego un nuevo proceso dialéctico, una "pelea chica" intraidentitaria por recursos fiscales que distrae de la usurpación efectiva de las tierras protegidas por la ley.

Un ejemplo: William Gysling, Gerente de Asuntos Externos de la Empresa Minera Doña Inés de Collahuasi, con indudable afán de transparencia, manifestó públicamente que el fisco, por intermedio del MBN, les había cobrado entre seis y siete millones de dólares por terrenos y servidumbres en 1997. En efecto, durante todo el tiempo que ha mediado desde la promulgación de la Ley Indígena, el MBN ha seguido ejerciendo actos de dominio sobre las tierras sometidas a proceso de catastro, es decir, se ha quedado con las principales prerrogativas del dueño, que permiten seguir negociando servidumbres y ventas de tierras fiscales directamente con las mineras. Y este es sólo un ejemplo: de haberse realizado el plan de saneamiento de las tierras aymaras y atacameñas en tiempo y forma, muchos más millones podrían haber ingresado a las arcas de las comunidades, que no a las del Estado. El problema se plantea entonces como una "negociación incompatible", donde el Estado es juez y parte. En efecto, no hace falta ser aficionado a teorías conspiracionistas para observar que al Estado no le conviene reconocer la propiedad indígena sino hasta después de haber vendido o gravado un máximo de tierras fiscales. Un criterio fundamental que sin duda se tomó en cuenta al demorar el catastro, es que de haberse titulado la tierra en la manera que había

des indígenas. Destacan casos emblemáticos como los de Ayquina, Turi y Toconce, que serán considerados en un próximo trabajo. 
sido solicitada, las comunidades territoriales hubieran podido, de algún modo, si no frenar la inversión minera, reorientarla un tanto. Posiblemente, las negociaciones con indígenas y el Estado habrían sido más arduas que con el solo MBN, quien incluso ha donado muchas tierras en las áreas reclamadas por los indígenas. Resulta a lo menos paradójico que mientras, por un lado, se esté regalando tierra a las mineras, por otro, se les esté ahora exigiendo el pago de regalías por estimar que no aportan lo que corresponde al país.

Debemos reconocer que, hasta ahora, el planteamiento es más teórico-jurídico que etnográfico: en realidad, aunque en los últimos 10 años el Estado rebajó unilateralmente las superficies a regularizar en casi un $60 \%$ de lo demandado originalmente, ningún dirigente atacameño o aymara ha sostenido alguna forma de reclamo territorial fuera del ámbito puramente administrativo. Con todo, el problema jurídico sirve, entonces, para reflexionar antropológicamente sobre lo que representa esta extraña carrera propietaria, sus contrapuntos retóricos y sus consecuencias identitarias. En efecto, ¿por qué las comunidades atacameñas no han podido (o no han querido, o no han sabido) hacer valer los derechos que la Ley Indígena consagra expresamente en su favor? Algunos dirigentes aymara y quechua entrevistados recientemente reconocen abiertamente haberse entrampado políticamente en "la pelea chica" por las platas que las mineras y el Estado han ido soltando a cuentagotas en su miríada de miniproyectos productivos y subsidios (herramientas privilegiadas en las políticas regionales de "dividir para reinar"). Bueno, y entonces, más allá de hectáreas y pesos más o pesos menos, ¿qué importancia tiene la diferencia entre la demanda territorial atacameña y la "transferencia" de tierras que dice hacer el Estado? ¿Qué rol juega la incumplida "salvaguarda" territorial de la ley, en la invención e imaginación identitaria atacameña? Desde el punto de vista antropológico interesa esta cuestión: ¿qué rumbos han tomado los procesos de diferenciación identitaria y propietaria locales desde la promulgación de la Ley Indígena en 1993? ¿Quiénes, en estos 10 años, han logran ponerse en posición de delimitar lo que es indígena de lo que no, culturalmente y territorialmente? ¿Cómo, y qué significa?

Queda que, aunque de manera cada vez más tenue, los habitantes de la región siguen desplegan- do complejas formas de apropiación, asignación y distribución de recursos, los que entreveran estilos personales y comunitarios de organizar la producción, tomar decisiones económicas informadas sobre la disposición de ingresos, así como redes de intercambio y parentesco autónomas que todavía implican viajes a larga distancia. El exclusivo conocimiento tradicional puneño es el que más caracteriza a los nativos de la zona, y constituye una forma de territorialidad no exclusiva, aunque claramente operativa y diferenciada, que continúa hasta el presente. Tal saber territorial podría caracterizarse por un "saberse el camino" en los difíciles parajes y poblaciones de la zona, su laberinto de huellas, quebradas y llanos, sus recursos diseminados en los contrafuertes y valles comarcanos. Ahora, los conocimientos tradicionales se están reemplazando por otros, que llevan por el difícil camino, por veredas y vericuetos burocráticos, y permiten sortear sus obstáculos. Insistimos que, aunque las sucesivas mareas burocráticas de formación de títulos de tierras demuestren una clara influencia en los modos de circulación de la propiedad, configurando de modo negativo el espacio andino en que supuestamente se desenvuelven en el norte de Chile (Gundermann 2003), éstas no han aniquilado cierto sustrato de nociones y prácticas territoriales distintivas. Este sustrato nocional está, en realidad, mucho más presente en la vida cotidiana de las personas que el que consagran las constituciones y las leyes, aunque no por eso son incompatibles con el mismo. El punto es que no solamente asistimos a competencias abiertas por recursos entre territorialidades, sino que también a una lucha soterrada entre modos distintivos de concebir las relaciones personales y territoriales.

El caso atacameño nos invita a olvidarnos, momentáneamente, de la verdad de la burocracia y sus papeles, para ensayar una definición antropológica de la propiedad que no se asiente en la entelequia estatal. Para Murphy y Roberts (1998: 6):

“explorar la relación [sic] entre las personas y las cosas requiere la formulación de un número de cuestiones precisas:

1. ¿Hasta dónde pueden distinguirse la administración o manejo de una cosa de su goce, de tal modo de corresponder a individuos o grupos diferentes? 
2. ¿En qué tipo de entidad están localizados el goce o la administración?

3. ¿Hasta qué punto el goce de una cosa es exclusivo de una persona, de un grupo de parentesco o de una unidad territorial (para mencionar tan solo las posibilidades más obvias)?

4. ¿Hasta qué punto los que administran o gozan de las cosas pueden disponer libremente de ellas?

5. ¿Cuáles son los principales modos de adquirir el acceso a, y el control sobre, las cosas?

6. De haberlos, ¿cuáles son los arreglos para la transmisión intergeneracional de las cosas?

7. ¿Hasta qué punto hay instituciones ya sea interiores al grupo o externas a éste, a quienes les concierne explícitamente vigilar la administración y goce de los recursos?"

Aunque esta lista de preguntas parezca ser directa y útilmente aplicable al caso que nos ocupa, sus autores presuponen la existencia de un cierto "estado de derecho" subyacente o una relación entre personas y cosas que es efectivamente respaldada por el grupo. ${ }^{32}$ Otros antropólogos han definido la propiedad de una manera más ambigua, como "hato" o "amarre" de poderes (Gluckman 1965; Hann 1998) que genera sentido propietario, llegándose incluso a confundir el derecho de propiedad con el poder de persuadir (Rose 1994). Menos axiológicas, tales definiciones de alguna manera también presuponen la existencia de un campo dialógico o idioma operado mediante el interruptor de lo legal/lo ilegal común a toda sociedad humana (Nader 2002; Teubner 1992 y 1997).

Tales propuestas definicionales, sin embargo, no se ajustan del todo a los datos antropológicos y jurídicos que he podido compilar respecto de las relaciones entre los agentes estatales y los indígenas en México, Chile y Bolivia; tal como en casi todos los países latinoamericanos, la propiedad es ante todo un objeto de tensiones y demandas cruzadas que rara vez se apoyan en algún consenso legitimador de la misma (¿de quién son los hidrocarburos bolivianos?). En este contexto, parece obvio que los títulos de propiedad (incluyendo toda suerte de amparos, composiciones, confirmaciones, adjudi-

32 En el sistema legal angloamericano se habla más fácilmente de "sentimientos y demandas compartidos" que de "estado de derecho". Véase Geertz (1983). caciones y concesiones) emanados, primero, de la Corona y luego de las entidades estatales que le sucedieron, han sido tan sólo utilizados como una de muchas estrategias de territorialización al alcance, uno entre tantos rituales y registros socioespaciales y políticos disponibles; pero, expresadas o reservadas, públicas o privadas, comunitarias o individuales, en la región atacameña hay muchas territorialidades que se interpelan. Y ¿qué pasa cuando hay más de un repertorio territorial o ritual (re)distributivo en juego, o cuando las nociones territorialidades que los forman "se hablan de largo" llegando a desconocerse mutuamente en aspectos fundamentales? El verdadero esfuerzo antropológico consiste en intentar considerar diversos modos de territorialización en un solo marco teórico y metodológico, en lugar de considerar a cada uno como un mundo o sistema cerrado separado. Esto tal vez permita desarrollar mejor el estudio comparativo de los regímenes y repertorios de valores territoriales y propietarios, junto a las relaciones que éstos tienen con las fenomenologías de identidad y exclusión que van generando y orientando. Como veremos, lo paradójico del asunto es que mientras el sentimiento étnico Estado-dependiente se ha ido fortaleciendo en San Pedro de Atacama, a lo largo de los mismos 10 años se ha reducido la territorialidad comunitaria y patrimonial que, según la Ley Indígena, lo sustenta. Por otra parte, el crecimiento del mercado de la tierra privada se ha traducido en la merma irremediable de los conocimientos biodiversos que integran y caracterizan la territorialidad atacameña (la lengua kunza se dio por perdida hace más de un siglo). Se podría pensar que la clave propietaria estatal ha desplazado aquella asociada a la memoria y saberes transmitidos en forma oral. Ahora abordaremos la etnografía del "quehacer estatal" con su micropolítica de ministerios, municipalidades y funcionarios en relación con autoridades comunitarias y asociativas indígenas, así como también con la masa restante de población flotante e inmigrante, de residentes sin identificación étnica o desterritorializados; todo, para entender mejor las relaciones entre poder, propiedad e identidad, y tal vez elucidar lo que los hace irse diferenciando e integrando en San Pedro de Atacama.

\section{Ley Indígena y autonomía territorial en San Pedro de Atacama}

Tras entregar Pinochet el gobierno de Chile, el tema territorial (incluyendo tierras, aguas y patri- 
monio arqueológico, entre otros) apareció como el principal tema pendiente por el cual diversos pueblos autóctonos reclamaron la promulgación de una Ley Indígena. ¿Cómo se explica que, lejos de ser solucionados, los urgentes problemas detectados y normados en esos años hayan sido solamente postergados, agravándose? ¿Por qué los dirigentes atacameños dicen que, en vez de disminuir, los problemas por aguas y tierras han crecido después de la promulgación de la Ley Indígena? ${ }^{33}$

La ley puso el tope organizativo territorial indígena al nivel de las comunidades, negando la posibilidad de que éstas se confederaran. Eso sí, se han constituido un sinnúmero de asociaciones no territoriales, de indígenas urbanos y migrantes, o creadas con fines específicos (p.e., culturales y económicos). Destaca la creación de una asociación de dirigentes de comunidades, aunque teniendo algún grado de influencia política regional, le está vedado asumir directamente la representación territorial de las comunidades. El hecho es que a pesar de la profusión de organizaciones atacameñas que han visto la luz desde la dictación de la Ley Indígena, ninguna de ellas ha demostrado interés en reclamar los derechos territoriales claramente consagrados en ella. Por otro lado, el Estado tampoco parece sentir apuro alguno con el tema territorial indígena en el norte: solito ha fijado la agenda catastral, así como la posibilidad de efectuar y verificar su cumplimiento. Así, mientras catastra y da en concesión cansinamente las tierras indígenas, el fisco ha podido acelerar y consolidar su rol territorial intermediario, vendiendo "sus" tierras, arenas y ripios, y estableciendo servidumbres baratas en favor de las poderosas

33 En agosto del año 2000 se elaboró un documento denominado Demandas Prioritarias de los Pueblos Atacameños (anónimo) que fue parcialmente recogido en otro documento de 18 de noviembre del mismo año, llamado Demanda Territorial del Pueblo Atacameño. Esta demanda fue suscrita por una autodenominada Comisión de Defensa de Aguas, Tierras y Cultura Atacameña integrada por 26 dirigentes de asociaciones y comunidades, para ser presentado al SEREMI de Bienes Nacionales de la II Región. Ahí se señaló la urgencia de realizar el postergado plan de saneamiento, y de preservar la integridad del territorio atacameño "que es uno solo y pertenece a todas nuestras comunidades, y no [reconocer] simples sitios o terrenos aislados a favor de una u otra comunidad, como se pretende hacer". Hasta donde sabemos, el MBN no respondió a dicho documento, y el catastro siguió con su tendencia expropiadora. mineras. A la par de este silencioso proceso de transferencia territorial, mineras y Estado se han granjeado un lugar especial en muchos corazones indígenas, costeando un sinnúmero de proyectos identitarios, eventos culturales y productivos, subvencionando así a las "asociaciones indígenas" regentadas por exclusivos clientes étnicos (verdaderos caciques postcoloniales del interior de la región). Mientras la élite etnopolítica local esté entretenida con los proyectos de que son beneficiarios inmediatos en términos de sueldos, casas, automóviles, ayuda a familiares, entre otros, los atacameños "del montón", con certificados o no, se han vuelto un cómodo y fragmentado interlocutor estatal de fachada, uno que carece de plataforma formal de liderazgo territorial más allá del nivel de la comunidad indígena (la Municipalidad sólo ejerce cierta tuición sobre los bienes nacionales de uso público localizados en la comuna, y no tiene prácticamente ninguna injerencia sobre los "terrenos fiscales vacuos").

La situación descrita no es de gran novedad: el reconocimiento de las tierras indígenas del norte de Chile sigue el mismo patrón de negación estructural (o racismo) que ha caracterizado el despojo de tierras indígenas en todas partes desde la hazaña de Colón. En este contexto, una élite local y regional asume el monopolio de la interlocución étnica con el Estado, quien le remunera por ello (p.e., con exenciones, privilegios, puestos públicos, o a través de miniproyectos productivos). Otros han estrechado vínculos con las mineras (La Escondida, CODELCO Norte, El Abra, Zaldívar). A pesar de resentir la asimetría estructural que impera en las negociaciones en que intervienen, algunos destacados líderes manifiestan estar relativamente satisfechos con su quehacer y buen pasar: algunos ahora incluso pueden mandar a sus hijos a estudiar a Calama. En general, han estado conformes con las transferencias a título gratuito o en concesión que el gobierno está haciendo (total, la plata llega por otros lados). Tan solo una minoría de dirigentes está consciente de que el asunto de la demanda territorial es urgente, y de fondo: los más entendidos dicen haber sido apurados por la CONADI a aceptar la reducida y apresurada solución estatal. ${ }^{34}$ Estos últimos dicen querer una asesoría jurídica

34 En una reunión de las autoridades de algunas comunidades beneficiarias en San Pedro de Atacama, éstas declararon que aceptaban las concesiones de uso de tierras fiscales porque era el mecanismo más expedito de asegurar sus re- 
independiente. En la práctica, todos están igualmente marginados de la toma de decisión en los proyectos con gran impacto regional. ¡Los atacameños son tan pocos en comparación con el número de personas que dependen de la territorialidad minera! Cualquiera de las empresas en cuestión probablemente tiene más empleados que el número total de atacameños que arroja la cuenta oficial. Además, mientras la territorialidad minera genera retornos incalculables en el extranjero (tanto, que hoy han sido puestos en tela de juicio por ciertos sectores del Estado que exigen el pago de royalties), las posibilidades de retorno territorial que les está siendo reconocido a los atacameños "del montón" apenas da para la agricultura de subsistencia subvencionada, peonaje asalariado o relaciones de dependencia económica respecto de la minería o de puestos estatales. Las posibilidades de movilidad social y territorial vehiculadas por medio de la educación o del trabajo en la empresa son todavía un sueño para la mayoría de menores ingresos. Los pudientes que mandan a sus hijos a estudiar afuera generalmente son los mismos que están hoy convertidos en brokers o intermediarios en proyectos territoriales de tipo turístico, minero o político, entre otros.

Retomando el título de este ensayo, se puede afirmar que las propiedades indígenas reconocidas en la ley no lo fueron como resultado de innatos e irreprimibles valores identitarios expresados por autoridades tradicionales atacameñas, o por algún movimiento social étnico. Muy por el contrario, tan sólo unos cuantos antiguos dirigentes saben del alcance territorial exacto de los aún incumplidos "transitorios" de la Ley Indígena. Nunca hubo algo así como un "fuego identitario" que haya empujado el postergado catastro de la tierra, y esto ha terminado favoreciendo la expansión y consolidación territorial del cluster minero. Como consecuencia de las apremiantes presiones y negociaciones sobre recursos locales, los intermediarios étnicos no han podido más que atrincherarse en interlocuciones subordinadas al poder estatal, en la "pelea chica". Agitando el señuelo de las tierras y de las aguas, la nueva institucionalidad indigenista logró cooptar a los primeros líderes de raigambre popular que emergían en el nuevo escenario democrático, constituyéndolos en sujetos políticos étnicos, funcionarios públicos y municipales ejemplares, con intereses amarrados a las prioridades y metas fiscales dictadas desde Santiago, Antofagasta, Calama y Chuquicamata.
Sin duda, la burocratización y demora en la implementación de los derechos de propiedad atacameños ha sellado su identificación oficial. En los hechos, el reconocimiento formal y retórico en tanto contraparte étnica "de fachada" consolidó las condiciones asimétricas de negociación local y regional sobre los recursos, consagrando de paso a los atacameños como una suerte de "modelo" de buen comportamiento étnico en el nivel nacional. Esta etnia goza la fama de ser relativamente participativa, exhibir altos niveles de asociatividad proyectista, además de ser pacífica, medianamente emprendedora y de trato fácil. Por supuesto que identificar, exoticizar, subsidiar, homogeneizar, acorralar retóricamente y amordazar con la ley a entidades territoriales con prácticas culturales tan variadas como próximas (familias y pueblos como los de Toconce, Caspana, Talabre, Machuca, Chiu Chiu y San Pedro de Atacama) ha tenido efectos negativos. ${ }^{35}$

Este ensayo ha querido ser la crónica de una etnia anunciada y su breve "luna de miel" con la ley de Estado que le dio vida jurídica. Imbuidos del proceso etnificante y con tal de mantener una palanca negociadora, algunos de los nuevos políticos atacameños que surgieron bajo el doble alero de las mineras y del Estado insisten en levantar campañas explícitamente racistas, basadas en un cómodo rechazo del "otro" a mano, el consabido afuerino usurpador de tierras locales ${ }^{36}$ Este recurso de política interna les ha dado dividendos políticos a esos dirigentes en sus relaciones de política externa proyectista regional y nacional, permitiéndoles colocar a su gente en puestos claves. Lo paradójico del asunto es que por este medio hay más gente atacameña en posiciones de poder que antes, y sin duda que esto ha mejorado el nivel de vida de mucha gente. Lo que no se ve,

cursos, pero que lo hacían "bajo reserva de hacer valer sus demás derechos patrimoniales en otro momento que estimaran oportuno".

35 Chiu Chiu pronto se transformará en un verdadero suburbio de Calama: un ex responsable provincial del MBN alcanzó a comprar un título sobre cientos de hectáreas en la vega, actualmente en proceso de loteo: "la viejita no sabía lo que tenía, pobrecita".

36 El régimen de la propiedad privada común a todos los chilenos se aplica también al caso atacameño, lo que ha planteado innumerables conflictos en torno al mercado local de tierras, muchos de ellos intraétnicos. El tema de la propiedad individual atacameña merece un estudio separado. 
en cambio, es una organización social con capacidad para alzar la bandera de la territorialidad atacameña o aymara en las regiones primera y segunda. Bueno, y alguien podría preguntar ¿y por qué debiera haberla? Es probable que, luego, los atacameños se despierten del idilio en una realidad desterritorializada, con más hijos y nietos, pero sin las propiedades comunitarias y patrimoniales que les garantiza la ley. Como sea, no podrán gozar de formas de autonomía colectiva si no logran un mayor control sobre los recursos territoriales (tangibles e intangibles) que hoy están en el limbo burocrático: autonomía y territorialidad son las caras de una misma moneda. La supuesta autonomía municipal paraestatal (desde 1980) y su permanente invitación al caciquismo y al clientelismo es todo lo contrario. La Municipalidad de San Pedro y las comunidades atacameñas no pueden entablar negociaciones simétricas con el Estado, o las mineras, sus dos interlocutores territoriales más directos. Avasallados por el capital o cooptados por la territorialidad intermediaria del Estado,

"los líderes indígenas que inicialmente fueran incorporados a la CONADI, y algunos por temor a perder sus cargos, han comprobado que pueden hacer y decir cada vez menos cosas, e incluso se han visto forzados a actuar en sentido contrario a los intereses de los pueblos que de hecho representan ante el Estado y que se supone no deben representar" (Barros 2000).

Aunque algunos de estos dirigentes creen firmemente haber hecho crecer lo atacameño (o lo aymara) desde el interior del Estado o con platas de la minería (y en verdad que ha mejorado la vida de muchos, y que algunos han tenido oportunidades económicas impensables hace 10 años) las voces y problemas de los que se podrían denominar atacameñas o atacameños del montón están completamente ahogadas en la insulsa retórica etnificadora y su consiguiente delirio Estado-dependiente. Como quiera que se les identifique, y por más que se les haya adscrito a la categoría poco imaginativa de etnia, los atacameños no se caracterizan por su autonomía respecto del Estado, aunque mantienen cierta "ontonomía" territorial desfalleciente, la que, precisamente, debió de haber quedado salvaguardada como efecto de la ley. Ahora, los dirigentes y representantes políticos y sociales ya se acostumbraron a ceder y componerse con minera y Estado (pienso particular- mente en el MBN). Al hacerlo, se han ido mimetizando con la huida hacia adelante que caracteriza la territorialidad estatal: una escasa consideración por lo que la doctrina jurídica internacional hoy llama "derechos intergeneracionales", nada menos que la suerte de todas las generaciones futuras.

La autonomía es esencialmente un hecho y no hay ley que la supla; por eso, la Ley Indígena en ciertos aspectos salió como un tiro por la culata, o un victoria pírrica, cercenando y sobrellevando la capacidad local para definir intereses y subjetividades territoriales colectivas y/o individuales (con o sin leyes). Así que para el caso atacameño sería más propio hablar de una heteronimia de derecho y de muy poca autonomía en los hechos. Hay una brecha estructural entre los espacios indígenas consagrados formalmente por la ley y las capacidades autonómicas del grupo agraciado. Sobre todo, la Ley Indígena ha hecho ganar y perder tanto presencia como tiempo y dinero a diversos líderes y autoridades indígenas por medio de una torre de Babel burocrática hecha de proyectos, catastros, reclamos, divisiones, cartografías, demandas, subsidios, juicios y sentencias especulativas. Ese es su logro mayor: haberse encarnado en las prácticas sociales locales.

Con todo, el análisis de caso nos conduce a una vertiente explicativa insuficientemente explorada, cual es, cómo los procesos históricos de etnificación son el resultado parcial de retóricas y procesos de expansión, contracción y diferenciación propietarios mediados por circuitos burocráticos (Barros 2003). Bien sabe el Rapporteur de las Naciones Unidas R. Stavenhagen (2002) que el problema característico de la actual retórica jurídica nacional y transnacional en torno a temáticas indígenas es ese rezago crónico o demora en la implementación, particularmente en cuanto a titulaciones y demarcaciones territoriales a favor de indígenas. Pero, ¿cómo estudiar la crónica demora en la implementación de las leyes a que se refiere Stavenhagen? Por implicación se entiende que los intereses del Estado y sus leyes ligados al capital se territorializan más rápido de lo que las pocas y dispersas normas en beneficio de los indígenas alcanzan a impedir, siempre cortas, inaplicadas y desfasadas. La política del tiempo (o de la demora) implícita en el tradicional "se acata pero no se cumple" se convierte así en una expresión de racismo y/o violencia estructural que, 
en alianza con el fenómeno simultáneo de la globalización y concentración del capital, refuerzan una micropolítica de la exclusión y doblez con una retórica propietaria.

A pesar de sus innegables logros, los que trabajan en las instancias internacionales saben que todo avanzar legal consagra cierto retroceder indígena desde el punto de vista de su autonomía territorial concreta (con el consecuente desvanecerse de soberanías intelectuales). Así, las retóricas jurídicas nacionales e internacional no sólo no han detenido los abusos tecnocráticos autoritarios ejercidos contra los indígenas que son presa intelectual del Estado, sino que, por el contrario, hasta cierto punto los ha reforzado mediante subvenciones distribuidas estratégicamente entre algunos dirigentes étnicos que se ven obligados a reproducir formas de doble discurso para mantener sus posiciones intermediarias. Lo interesante del asunto es que ya en la época colonial los analistas sociales planteaban idénticas cuestiones: los artefactos burocráticos, su flujo y su verificación, su anacronismo inherente, ya eran considerados una componente estructural del sistema tributario que impone definiciones de lo indígena en contraposición con las posibilidades de acceso a trabajo, vivienda, salud, educación, capital, tecnología, justicia, información, entre otros, y sus combinaciones y distribuciones óptimas. ${ }^{37}$

Chile es uno de los pocos países de América Latina que no ha reconocido efectivamente el dominio indígena preexistente. Esta falla estructural en nuestro edificio jurídico y político hace que se

\footnotetext{
37 La Recopilación de Leyes de Indias y la Novísima Recopilación otorgaban garantías y reconocían libertades mucho más radicales que las leyes indígenas de hoy. Se asignaban intérpretes y se reconocían formas de gobierno comunal con jurisdicciones exclusivas. También se reconocieron resguardos, reservas y fundos legales, y a los indígenas se les permitía elegir a sus gobernadores cuando no se reconocía la autoridad hereditaria de caciques y principales. Los sujetos indígenas estaban, en principio, exentos de gastos judiciales y en sus causas podían pedir la asistencia de amigos y contar con el apoyo de peritos, e incluso de un trato legal especial de parte de la temible Inquisición. De hecho, la Corona española llegó a celebrar verdaderos tratados con algunos pueblos, como con los lonkos mapuche; también, distinguió niveles de autonomía territorial diferenciados según las costumbres nativas, como en Colombia respecto de los indios y sus resguardos, o como con los Mixes de Oaxaca y sus "tierras no realengas ni ahora ni en ningún tiempo" (Barros 2003).
}

repitan una y otra vez los mismos abusos autoritarios, pues los indígenas no pueden ni tienen cómo ampararse formalmente en algún derecho que trascienda el ámbito estatal. Este proceso de segmentación y tensión ha sido alimentado por fuentes diferentes, y ha tenido efectos en ámbitos insospechados. En efecto, el camino que ha venido tomando el debate etnopolítico en nuestro país parece haber derivado en una mayor visibilidad pública de los fundamentalismos identitarios, lo que no ha necesariamente conducido a un mejor entendimiento o a una mayor equidad social entre los involucrados o a mejorar las relaciones de convivencia. A pesar de las buenas intenciones declaradas, los términos de los supuestos diálogos y las negociaciones mismas han sido efectuados en términos legalistas y autoritarios, como en el caso de la Provincia de El Loa, en el cual agentes ministeriales del Estado han definido lo atacameño de manera arbitraria e ilegal. Al igual que en el pasado colonial, la actual política de titulación en favor de los indígenas en realidad ha sido un dumping a los conocimientos, prácticas y valores territoriales locales: como en tantas ocasiones, las tierras indígenas terminan tituladas a costa de grandes pérdidas.

Por eso, se ha procurado el alejamiento de una visión objetivada de la propiedad, o de papel, que tales agentes catastrales tienden a presentar: intentamos, en cambio acercarnos a las territorialidades que subyacen e informan cualquier práctica diferenciadora que determine modos exclusivos de apropiación respecto de recursos puntuales (materiales e inmateriales). Intentamos seguir los patrones y formas de cambio donde éstos de alguna manera ocurren "en la frontera", si se quiere. Parece más fructífero volcarse ahora a analizar las constantes en los procesos de diferenciación o titulación, más que los momentos "catastrales" de los mismos. Retomando una descripción de las pequeñas haciendas del valle de Quillagua, que a fines del siglo XIX eran llamadas "cercos" por los naturales (Billinghurst 1886: 60), hemos intentado evocar los procesos que mueven, hacen caer o correr los cercos discursivos territoriales, y sus efectos en procesos identitarios. Interesan las retóricas que se despliegan e invocan, y en qué momentos demográficos, económicos y políticos.

En el plano internacional, el proceso de titulación de los aborígenes australianos tal vez sea el que más útilmente se pueda comparar al de los ataca- 
meños. ${ }^{38}$ Los tribunales australianos, anclados en el common law, no han podido menos que reconocer la preexistencia y vigencia de nociones de dominio aborigen, descartando para siempre la ficción racista de la terra nullius que sigue aplicándose en nuestro país (literalmente "tierra de nadie", que curiosamente es también una de las definiciones clásicas de frontera). A partir de este giro australiano, se ha venido siguiendo una serie de negociaciones que han permitido a observadores afirmar que la autodeterminación aborigen se plasma precisamente en los procedimientos de titulación. Los indígenas están envueltos en un proceso de titulación permanente con el Estado, negociaciones que, sin perjuicio de estar marcadas por un alto nivel de asimetría tecnocrática, permiten evaluar los aspectos procesales de la justicia territorial cuando hay diversas territorialidades en juego, y observar cómo operan sus mecanismos de diferenciación (Barros 2003; Agius et al. 2003 Ms). Pero el "saneamiento" chileno ha sido diferente: en el caso atacameño se le ha llamado "catastro" y "ordenamiento", aplicándose criterios que el caso Mabo y la doctrina jurídica internacional han denunciado como abiertamente racista.

\section{Conclusión: Estado actual, ley envolvente, la cuestión de los títulos y otros cercos de papel}

"Primero en tiempo, primero en derecho" solía repetirse A. Regino (eminente abogado Mixe y mexicano). Convengamos finalmente con él que las relaciones territoriales indígenas son anteriores al Estado. Es más, existe una multiplicidad de formas de organizar relaciones sociales y territoriales que no se conciben como dependientes del Estado. En este sentido, las territorialidades atacameñas han sido efectivamente menoscabadas: aunque el dominio preexistente y perpetuo sobre su región cultural está salvaguardado por la ley, éste ha ido caducando por la fuerza de los hechos tecnocráticos. Así, no más que un puñado de agentes fiscales ha logrado vulnerar profundamente los derechos indígenas, demorando la implementación del catastro ordenado por la Ley Indígena y rematando el proceso con reducidas transferencias de polígonos y concesiones de uso. Las formas locales de ocupación y apropiación han sobrevivido como territo-

38 Véase, por ejemplo Myers (1991) en relación con Agius y colaboradores (2003 Ms). rialidad regional, y la memoria resultante no se asienta ni se ha quedado en los sucesivos títulos (que son, más bien, medios de intercambio, artefactos legales que facilitan el registro, la consolidación y el aumento de la circulación propietaria en clave estatal). Como en la mayor parte del continente americano la memoria oral indígena mantiene al cerro por dueño: ¿qué autoriza al fisco para desconocer ese tipo de relaciones? ¿Quién puede negar las relaciones propietarias preexistentes? El fisco no pudo extinguir derechos de propiedad que le eran anteriores, y las leyes sobre inscripción de la propiedad nunca fueron expropiatorias. Este canon propietario integra hoy percepciones difusas de dominio que determinan en parte el uso, transferencia y administración de recursos locales, así como diversas jerarquías de acceso y conocimiento, conformando un campo de acción política que se encarna tan solo parcialmente en la variedad de organismos y asociaciones paraestatales e iniciativas individuales que han surgido desde la Ley Indígena.

¿Cuánto dinero habrán percibido las cajas fiscales que maneja el MBN desde el 5 de octubre de 1996 (fecha en que venció el plazo para realizar el plan de saneamiento), por concepto de ventas de tierras y constitución de servidumbres en favor de las empresas mineras? Un movimiento etnopolítico consecuente con las generaciones futuras exigiría una moratoria a la venta de tierras fiscales u otorgamiento de nuevas concesiones mineras (exploración y explotación), así como de aguas (exploración y explotación de aguas subterráneas) en tanto no se resuelva lo de la propiedad patrimonial indígena. Las autoridades atacameñas que han intentado hacerlo han sido acalladas por otras. ¿Por qué ninguna comunidad atacameña ha exigido al Estado el cumplimiento de la ley? ¿Por qué nadie hace valer su explícita responsabilidad por la demora y el pernicioso desfiguramiento de las territorialidades patrimoniales indígenas? Lo que está en juego en estos momentos es la posibilidad de que los atacameños del futuro (y los gobiernos territoriales locales en general) tengan mayor poder para decidir sobre la calidad de vida de sus representados y las generaciones venideras. El fisco puede ser condenado a indemnizar a las comunidades indígenas por todo el daño que haya surgido de la demora en cumplir con sus obligaciones legales y territoriales ¿Qué nueva deuda histórica se acumula mediante la política de los hechos consumados, al calor del "se acata pero no se cumple" de los derechos indí- 
genas?, ¿acaso es cuantificable? A la larga, tal vez lo sea solamente en términos étnicoadministrativos, es decir, que sirva para endurecer la identidad así empobrecida, hasta romperla.

Propongo que, tal como lo hemos empleado aquí, el concepto de territorialidad (que no territorio) responde en parte al desafío que dejó planteado J. L. Martínez; esto es, permite estudiar cómo se constituye, caracteriza y reproduce la fenomenología de "diferencias compartidas" en lo que este autor ha denominado sistema de "interdigitación multiétnica" y su "gran red de múltiples lazos y trazados, con (...) una movilidad constante" (1998: 127-150). Pero esta vez incluyendo al Estado. Estoy pensando en las nuevas territorialidades donde las distinciones y retóricas entre lo público y lo privado pierden importancia frente al surgimiento de "sistemas de colaboración abiertos" para el manejo de recursos locales sobre la base de "bases de conocimiento". Estos estarían en la medida de retribuir adecuadamente tanto los conocimientos tradicionales y científicos como la soberanía intelectual, creencias y esfuerzos territoriales, con una autoridad distributiva más imparcial que la que ofrece actualmente el Estado (o las mineras, para el caso). Se puede visualizar la síntesis de las estructuras, proyecciones y acciones territoriales personales y sociales, legales y estatales como a un complejo calendario, o una "espiral territorial" que conjuga fechas y elementos legales, burocráticos, religiosos, agrícolas, de parentesco e individuales, una agenda marcada por recorridos y reuniones más o menos importantes con otras personas, y un sinnúmero de rituales materiales e intelectuales que alimentan el flujo de información que transmuta y se distribuye en beneficios (Figura 3). Nada obsta, en principio, que los beneficios económicos correspondientes a los flujos territoriales lo sean de manera sustentable, sin necesidad de más planificación centralizada, pero tampoco esclavizándose a la razón maximizadora del solo homo economicus. En la época de la llamada "economía del conocimiento", puede pensarse en lo que, con algo de cortedad imaginativa, he llamado "comercio justo con el conocimiento".

Los nuevos títulos que se están entregando a los atacameños son, de facto, un pésimo negocio en ese sentido: mientras debían salvaguardar el do- minio atacameño, regularizándolo, el MBN se apresuró en vender, ceder e incluso regalar dócilmente un máximo de superficies, aparejadas o no a los subsuelos de las mineras.

Dando la vuelta completa, lo dicho hasta ahora nos lleva a pensar que los alicaídos derechos humanos de los pueblos indígenas harían bien en transformarse en una noción de derechos procesales: los indígenas en Chile no han tenido las garantías de un "debido proceso" territorial. Queda que, con o sin títulos formales, "propiedad", desde el punto de vista antropológico, es ante todo la proyección de un "saber territorial" a la vez personal y social, el "conocer su camino" en una red de redes de conexiones e incomunicaciones territoriales que pueden ser significadas por elementos en apariencia tan simples como un cerco (sea este de papel o información electrónica compuesta de bits).

Futuras investigaciones podrían intentar caracterizar, ya no los patrones históricos de asentamiento y sus "aparatos de complementariedad" -tarea recientemente resumida con maestría por Martínez (1998)-, sino que los eventuales patrones históricos de movilidad y diferenciación territorial, propietarios y, en consecuencia, identitarios o étnicos que operan en la zona en estudio. Por lo tanto, no sólo queda por definir y caracterizar el histórico "problema de los límites" en la forma pautada por Castro y Martínez (1996), sino que tratar de reconstituir el rastro de artefactos (entre ellos, los títulos) que va dejando tal proceso para entender cómo las territorialidades se van integrando a la vez que diferenciando, y por medio de qué dobleces escriturales. Es posible que, con base en las herramientas, papeles, memorias y rastros que dejaron los antepasados, se puedan ir elucidando algunas características operativas de este hipotético calendario territorial. Un estudio minucioso de las cuentas cortas y largas de la historia a través de los procesos de titulación permitiría esbozar una redefinición antropológica radical de la propiedad y su relación con diversos procesos identitarios, particularmente en la primera y segunda región. Con este ensayo, espero además haber aportado algunos elementos para reflexionar sobre viejos problemas de justicia territorial asociados con los pueblos indígenas de América Latina. 


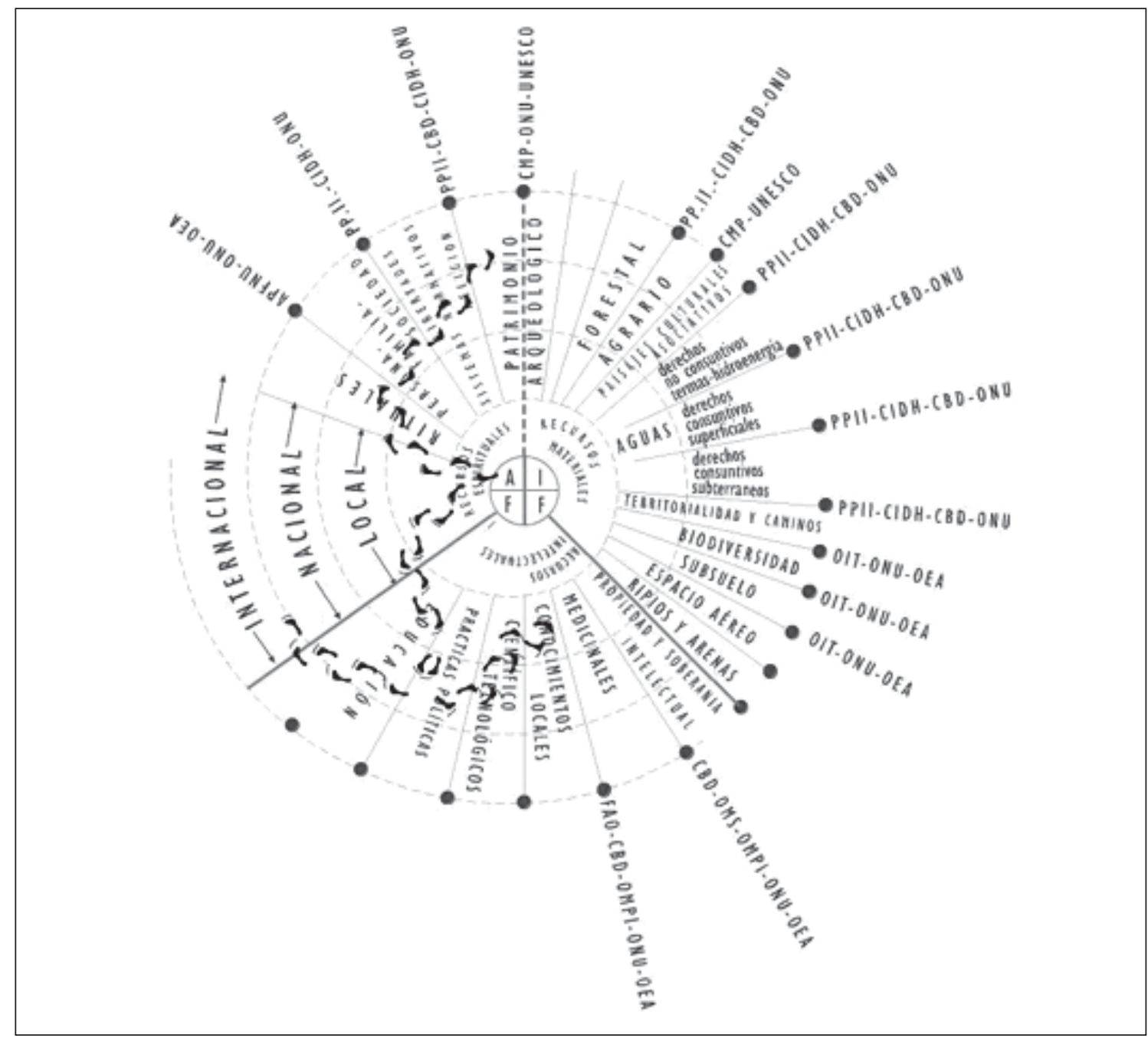

Figura 3. Representación imaginaria, indicativa e incompleta de un espiral o "calendario" legal envolvente en torno a una comunidad local indígena cualquiera. En el centro, A=Autoridades, I=Individuos, F=Facción. Los nodos y cruces que la forman representan encrucijadas de poder e instituciones burocráticas que forman el recorrido de las personas (huellas de pies) entre el centro y los niveles jurídicos local, nacional e internacional. Se señalan algunas de las leyes e instituciones leyes que afectan a las comunidades para demostrar la casi imposibilidad estructural de atender apropiadamente los intereses que las atañen en relación con el rol intermediador del Estado. Se mencionan a título indicativo algunos acrósticos correspondientes a organizaciones del plano internacional con incidencia en asuntos relativos a los pueblos indígenas (PP II=Pueblos Indígenas; CIDH=Comisión Interamericana de Derechos Humanos; OMPI=Organización Mundial de la Propiedad Intelectual; CMP=Convención Mundial del Patrimonio; OMS=Organización Mundial de la Salud; FAO=Food and Agriculture Organization; OIT=Organización Mundial del Trabajo; CBD=Convención sobre la Biodiversidad; ANUPF=Agencia de las Naciones Unidad para la Planificación Familiar). 


\section{REFERENCIAS CITADAS}

AGIUS, P., HOWITT, R. JARVIS, S, WILLIAMS, R., 2003 Ms. Doing native titles as self-determination: Issues from native title negotiations in South Australia. Ponencia presentada en septiembre de 2003 en la International Association for the Study of Common Property, Pacific Conference, Brisbane, Queensland.

ALMEYDA, A., 1940. La constitución de la propiedad según un jurista indiano. Revista Chilena de Historia y Geografía $97:$ 94-132.

ALVAREZ, R., 1995. The Mexican-US border: The making of an anthropology of borderlands. Annual Review of Anthropology 24: 447-70.

ARDREY, R., 1966. The territorial imperative; a personal inquiry into the animal origins of property and nations. Atheneum, Nueva York.

BARROS, A., 1998. Desarrollo y Pachamama: Paisajes conflictivos en el Desierto de Atacama. Estudios Atacameños 13: 75-94.

--1998 Ms. Desert Bio-scape: Cultural diversity in the Atacama Desert-Chile. Ponencia presentada en septiembre de 1998 en el Simposio Internacional "Natural" Sacred Sites-Cultural Integrity and Biological Diversity, UNESCO, París.

-2000. Autonomía y territorio. Actas del XII Congreso Internacional de la Unión Internacional de Ciencias Antropológicas y Etnológicas, Comisión de Derecho Consuetudinario y Pluralismo Legal: Desafíos en el Tercer Milenio, pp. 548-554. Editorial Lom, Santiago.

-2003. To abide by unkept laws: Title negotiation amongst the Mixe of the Mexican Isthmus. Tesis Doctoral, Darwin College, Cambridge University, Cambridge.

BARTH, F., 1969. Ethnic groups and boundaries. Little Brown, Boston.

--2000. Boundaries and connections. En Signifying identities: Anthropological perspectives on boundaries and contested values, A. P. Cohen (Ed.), pp. 17-36. Routledge, Londres.

BASSO, K. H., 1996. Wisdom sits in places; notes on a western Apache landscape. En Senses of place, S. Feld y K. H. Basso (Eds.), pp. 53-90. School of American Research Press, Santa Fe.

BENDER, B. (Ed.), 1993. Landscape: Politics and perspectivas. Berg, Oxford.

BILLINGHURST, G., 1886. Estudio sobre la geografía de Tarapacá. Imprenta de "El Progreso", Santiago.

CASEY, E. S., 1996. How to get from place to space. En Senses of place, S. Feld y K. H. Basso (Eds.), pp. 13-52. School of American Research Press, Santa Fe.
CASTRO, V., 2002. Ayquina y Toconce: Paisajes culturales del norte árido de Chile. En Paisajes culturales en los Andes, E. Mujica (Ed.), pp. 193-208. UNESCO, Lima.

CASTRO, V. y J. L. MARTINEZ, 1996, Poblaciones indígenas de Atacama. En Culturas de Chile. Etnografía, J. Hidalgo, V. Schiappacasse, H. Niemeyer, C. Aldunate y P. Mege (Eds.), pp. 68-110. Editorial Andrés Bello, Santiago.

DAIREAUX, M., 1963. Melgarejo. Editorial Orbe, Santiago.

DELEUZE, G. y F. GUATTARI, 1980. Mille plateaux: Capitalisme et schizophrénie II. Collection Critique. Les Editions de Minuit, París.

-1991. Qu'est-ce que la philosophie? Collection Critique. Les Editions de Minuit, París.

DIEZ de VELASCO, M., 1983. Instituciones de Derecho Internacional Público, Tomo I. Editorial Tecnos S. A., Madrid,

DOUGNAC, F., 1975. La legislación aplicable a los indígenas del Norte Grande chileno. Norte Grande 1 (3-4): 437-444.

ESCALONA AGÜERO, G. DE, 1647. Gazofilacio Regium Perubicum. Imprenta Real, Madrid.

FELD, S. y BASSO, K. (Eds.), 1996, Senses of place. School of American Research Press, Santa Fe.

GEERTZ, C., 1983. Conocimiento local: Hecho y ley en la perspectiva comparativa, en su "conocimiento local". Paidós, Barcelona.

GLEDHILL, J., 2002. Los pasos difíciles a la ciudadanía amplia: Más allá de la transitología. En Ciudadanía, cultura política y reforma del Estado en América Latina. Colección Memorias. IFE-El Colegio de Michoacán, México D. F.

GLUCKMAN, M., 1965. Politics, law and ritual in tribal society. Blackwell, Londres.

GREENHOUSE, C., 1996. A moment's notice: Time politics across cultures. Cornell University Press, Ithaca y Londres.

GUNDERMANN, H., 2002. San Pedro de Atacama: Actores, procesos, imaginarios. En Retrato hablado de las ciudades chilenas, B. Guerrero (Ed.), pp. 47-62. UNAP-Centro de Investigaciones Barros Arana, Santiago.

-2003. La formación del espacio andino en Arica y Tarapacá Revista de Historia Indígena 7: 87-138.

HANN, C. (Ed.), 1998. Introduction: The embeddedness of property. En Property relations: Renewing the Anthropological Tradition. Cambridge University Press, Cambridge. 
HIDALGO, J., 1986. Indian society in Arica, Tarapacá and Atacama, 1750-1793, and its response to the Rebellion of Tupac Amaru. Tesis Doctoral, Universidad de Londres, Londres.

HIRSCH, E. y M. O'HANLON, (Eds.), 1995. The Anthropology of landscape: Perspectives of place and space. Clarendon Press, Oxford.

INGOLD, T., 1986. Territoriality and tenure: The appropriation of space in hunting and gathering societies. En The Appropriation of nature: Essays on human ecology and social relations, T. Ingold (Ed.), pp. 130-164. Manchester University Press, Manchester.

-2000. The perception of the environment: Essays on livelihood, dwelling and skill. Routledge, Londres.

LIFFMAN, P. M., 2002. Huichol territoriality: Land claims and cultural representation in Western Mexico. Tesis Doctoral, Department of Anthropology, University of Chicago, Chicago.

MARTINEZ, J. L. (Transcriptor), 1992. "Expediente sobre lo actuado a petición de Juan Velázquez Altamirano por haberse apaciguado los indios del valle de Atacama en el Perú”. Estudios Atacameños 10: 12-15.

-1998. Pueblos del chañar y el algarrobo. Los atacamas en el siglo XVII. Ediciones de la Dirección de Bibliotecas, Archivos y Museos, Santiago.

MARTINEZ, M. A., 1999. Final report: The study on treaties, agreements and other constructive arrangements between States and indigenous populations. UN document E/CN.4/ Sub.2/1999/20.

MERLEAU-PONTY, M., 1981 [1945]. Phénomenologie de la perception. Gallimard, París.

MINISTERIO DE BIENES NACIONALES-CINPRO, 1996 Ms. Informe de Avance ${ }^{\circ} 1$ del Proyecto Ordenamiento Catastral de las Comunidades Indígenas del Altiplano de la II Región.

MUÑOZ, B., 1999. Derechos de propiedad y pueblos indígenas en Chile. En la Serie Desarrollo Productivo n ${ }^{\circ} 60 \mathrm{de}$ la División de Desarrollo Productivo y Empresarial de la CEPAL. CEPAL, Santiago.

MURPHY, W. T. y S. ROBERTS, 1998. Understanding property law. Sweet and Maxwell, Londres.

MYERS, F. R., 1991. Pintupi country, Pintupi self: Sentiment, place, and politics among western desert aborigines. University of California Press, Berkeley.

NADER, L., 2002. The life of the law. University of California Press, Londres.

OTS CAPDEQUI, J. M., 1959. España en América: El régimen de tierras en la Epoca Colonial. Fondo de Cultura Económica, México D. F.
PAZ SOLDAN, M. F., 1878. Verdaderos límites entre el Perú y Bolivia. Imprenta Liberal, Lima.

RAIMONDI, A., 1879. El Perú. Vol. 3, Historia y Geografía. Imprenta del Estado, Lima.

RILES, A., 1994. Representing in-between: Law, anthropology and the rhetoric of interdisciplinarity. University of Illinois Law Review (3): 597-650.

-1999. The view from the international plane: Perspective and scale in the architecture of colonial International Law. En Laws of the Postcolonial, E. Darian-Smith y P. Fitzpatrick (Eds.), pp 127-144. Michigan University Press, Ann Arbor.

2001 Ms. Resetting: Property as instrument. Ponencia presentada en abril de 2001 en el Simposio Internacional $\mathrm{n}^{\circ} 128$ de la Fundación Wenner-Green, Changing property relations at the turn of the millennium, Ronda.

RIVERA MARIN DE ITURBE, G., 1983. La propiedad territorial en México 1301-1810. Siglo XXI Editores, México D. F.

ROSE, C. M., 1994. Property and persuassion: Essays on the history, theory and rhetoric of ownership. Westview Press, Oxford.

ROSEN, L. 1997. The right to be different: indigenous peoples and the queso for a unified theory. The Yale Law Journal 107 (191): 227-259.

RUIZ-TAGLE, E., 1992. Bolivia y Chile: El conflicto del Pacífico. Editorial Andrés Bello, Santiago.

SACK, R. D., 1986. Human territoriality. Its theory and history. Cambridge University Press, Cambridge.

SAIGNES, T., 1985. "Algún día todo se andará": Los movimientos étnicos en Charcas (siglo XVII). Revista Andina 3/2: 425-450.

SANCHEZ-ALBORNOZ, N., 1978. Indios y tributos en el Alto Perú. Instituto de Estudios Peruanos, Lima.

SOLANO, F. DE, 1984. Cedulario de tierras: Compilación de Legislación Agraria Colonial (1497-1820). UNAM, México D. F.

SOTOMAYOR, R., 1874. Estudio Histórico de Bolivia. Imprenta Andrés Bello, Santiago.

-1912. La Legación de Chile en Bolivia, desde setiembre de 1867 hasta principios de 1871. Imprenta de San José, Santiago.

STAVENHAGEN, R., 2002. Report of the Special Rapporteur on the situation of human rights and fundamental freedoms of indigenous people, Mr. Rodolfo Stavenhagen. Selected summaries of communications examined by the Special Rapporteur in 2001/2002. UN document E/CN.4/ 2002/97. $4^{\text {th }}$ of February 2002. 


\section{ALONSO BARROS VAN H.}

STRATHERN, M., 1999. Property, substance and effect: Anthropological essays on persons and things. The Athlone Press, Londres.

SUTTON, P. 1996. The robustness of aboriginal land tenure systems: Underlying and proximate customary title. Oceania 67 (1): 7-29.

TEUBNER, G., 1992. The two faces of Janus: Rethinking legal pluralism. Cardozo Law Review 13 (5): 14431462.
_- (Ed.), 1997. Global law without a State. Dartmouth, Aldershot.

TILLEY, C., 1994. A phenomenology of landscape: Places, paths and monuments. Berg Publishers, Oxford, Providence.

\section{Documentos}

Tratado de Paz, Amistad y Comercio celebrado con Bolivia en Santiago el 20 de octubre de 1904, Artículo II, inciso 21.

Corte Permanente de Justicia Internacional, Serie B, ${ }^{\circ} 6$. 